Research Article

\title{
The Electropolishing of C-Steel in Orthophosphoric Acid Containing Methanolic Plant Extract
}

\author{
Asia A. Taha (iD, Fatma M. Abouzeid (iD, Mohamed M. Elsadek (iD, and Yasmeen M. Othman (iD
}

Chemistry Department, Faculty of Science, Alexandria University, Alexandria, Egypt

Correspondence should be addressed to Fatma M. Abouzeid; fatma.abouzeid@yahoo.com

Received 7 February 2020; Revised 25 October 2020; Accepted 7 November 2020; Published 17 December 2020

Academic Editor: Barbara Gawdzik

Copyright (C) 2020 Asia A. Taha et al. This is an open access article distributed under the Creative Commons Attribution License, which permits unrestricted use, distribution, and reproduction in any medium, provided the original work is properly cited.

Plant extracts have been regarded as "green" alternatives as additives for metal electropolishing improvement. Therefore, understanding the electrochemical properties and the reaction mechanisms of the electroactive compounds from the plant extracts is necessary to further explore the mechanism and application of the plant extract-based additives for metal dissolution. The C-steel electropolishing behavior in orthophosphoric acid using the galvanostatic polarization and weight loss methods was ascertained. This was inspected via anode potential-limiting current relationship measurement and comparison in a solution of regularly mounting concentrations (from 50 to $1800 \mathrm{ppm}$ of methanolic marjoram, coriander seeds, chamomile, and guava leaves extract), and the influence of temperature on the dissolution kinetics was investigated. Surface morphologies, roughness, and reflection of investigated specimens were inspected with a scanning electron microscope (SEM), profilometry, and Vis-IR spectroscopy. Addition of methanolic plant extract to the electropolishing solution results in a lower limiting current. Retardation percentage gained from mass loss measurement is comparable with those obtained from measurements of galvanostatic polarization. Addition of $500 \mathrm{ppm}$ of marjoram, coriander, chamomile, and guava leaves increases the degree of surface brightness and reflectance to $64.9,56.59,27$, and 24.5 , respectively, relative to electropolishing electrolyte-free solution 16 . The roughness (Ra) decreased from $2.7 \mu \mathrm{m}$ to $0.52 \mu \mathrm{m}$ without addition of any material. Ra values are $0.28,0.23,0.21$, and $0.17 \mu \mathrm{m}$ in the presence of guava leaves, chamomile, coriander seeds, and marjoram.

\section{Introduction}

The electropolishing (EP) method is an extremely proficient process for brightening and cleaning of metals and alloys. It has obtained great consideration owing to its realistic and educational curiosity. EP is achieved via metal surface anodic dissolution controlled in an appropriate electrolyte and can improve planarization efficacy of the metal surface $[1,2]$, where the peaks and valleys depth differences are reduced $[3,4]$. It classically arises at the limiting current of mass transfer process, where the surface of metal becomes silky and even where the peaks and valleys depth differences are reduced $[3,4]$. It classically arises at the limiting current of the mass transfer process, where the surface of metal becomes silky and even. Concurrently, throughout EP, several etched pits and defects over the metal surface can be formed owing to oxygen gases evolution adjoining to the anode surface at a potential elevated than the limiting current plateau $[5,6]$. To reduce the incidence of surface defects formed on C-steel during EP, different additives were added to the polishing bath.

The progression is controlled via diffusion, dependent on the concentration incline forming a discriminating electrochemical dissolution and enhancing steel planarization efficiency, where the peaks and valleys depth variations are removed [7]. It characteristically happens at the limiting current of mass transfer at extreme anodic potential, since the metal surface is leveled. Concurrently, throughout the EP process, some blemishes and depths above the metal surface can be shaped owing to oxygen gas evolution greatly nearby to the surface at elevated electric potential $[8,9]$.

The polishing efficiency depends on the rate of $\mathrm{Fe}^{2+}$ ions mass transfer from the diffusion layer to solution bulk determined via the limiting current value. The mass transfer 
rate is a function of the relative ionic mobility, anode geometry, temperature, and electrolyte physical properties. Also, the concentration of the polishing bath electrolyte was examined [8].

C-steel is extensively used in all kinds of industry as an important construction material, and corrosion of C-steel is known to occur specially in acidic environment such as the cleaning, picking, oil well acidification, and descaling process. It is a major task to control the C-steel corrosion for both corrosion scientists and material technologists.

The employment of plant parts extractions for the embarrassment of the metal dissolution has some advantages over the use of some organic/inorganic inhibitors because they are nontoxic, cheap, and environmentally friendly. Consequently the goal of this research is to inspect the C-steel dissolution performance in the presence of methanolic plant extract which is a low -cost material, biodegradable, and environmentally friendly. The investigated compounds are of interest because of their safe use, also containing electronegative atoms such as $\mathrm{O}$ in their molecules, and being relatively cheap and biodegradable.

\section{Procedures}

2.1. Solution Preparation. $8 \mathrm{M} \mathrm{H} \mathrm{H}_{3} \mathrm{PO}_{4}$ was prepared via analytical-grade $\mathrm{H}_{3} \mathrm{PO}_{4}(85 \%$ w/w) dilution with double distilled water with a measured resistivity $>18 \mathrm{M} \Omega / \mathrm{cm}$. Preparation of the natural products was by methanol. All chemicals were supplied by $\mathrm{BDH}$ Chemicals Ltd. All experiments were performed in $8 \mathrm{M} \mathrm{H}_{3} \mathrm{PO}_{4}$-free solution and $8 \mathrm{M} \mathrm{H}_{3} \mathrm{PO}_{4}$ containing several concentrations of natural compounds (50-1800 ppm).

2.2. Material Sample Composition. The C-steel composition in weight percent was as follows: C: $0.2, \mathrm{Mn}: 2.6, \mathrm{Si}: 0.33, \mathrm{~S}$ : 0.04, P: 0.039, and Fe: balance.

2.3. Methanolic Plant Extracts Preparation. Marjoram, coriander seeds, chamomile, and guava leaves were purchased from the local market, washed with distilled water, air dried, and separately grounded into a powder using a blender. $25 \mathrm{~g}$ of the powdered samples was soaked in $500 \mathrm{ml}$ methanol for one week at room temperature. The mixtures were filtered to obtain sample extracts. This stock plant extract was kept in a refrigerator. The stock solution concentration was determined by evaporating a known volume of the filtrates to eliminate the methanol totally and weighing the residue.

2.4. Electrochemical Measurements. The cell used consists of a rectangular plexiglass container with a base of $15 \times 5$ and a height of $10 \mathrm{~cm}$ with carbon steel sheets electrodes of $10 \mathrm{~cm}$ height and $5 \mathrm{~cm}$ width. Electrode separation was $15 \mathrm{~cm} .6 \mathrm{~V}$ D.C. power supply, a high impedance voltammeter,a variable resistance, and a multirange ammeter were connected in series with the cell as the electrical circuit. The temperature was adjusted via placing the cell in a thermostatic water bath at several temperatures, $\left(20,30,40\right.$, and $\left.50^{\circ} \mathrm{C}\right) \pm 0.5^{\circ} \mathrm{C}$.
2.5. Chemical Measurements. C-steel specimens used in mass loss procedures were mechanically cut into $2 \times 2 \times 0.3 \mathrm{~cm}^{3}$ pieces, then abraded with $180,320,800$, and 1200 grades of emery papers, washed using deionized water, degreased with ethanol, and dried. The specimens were weighed before and after electropolishing galvanostatic measurements. Trials were performed in triplicate for reproducibility.

\subsection{Surface Characterization}

2.6.1. Scanning Electron Microscope. The analysis by using a SEM (JEOL JSM-5300 Scanning Electron Microscope.) was carried out on the surface of C-steel samples with and without the optimum concentration of plant extract.

2.6.2. Profilometer Measurements. The quantitative surface roughness $\left(R_{a}\right)$ was measured via stylus profilometers (Talysurf i60). The long cutoff wavelength sampling was $0.25 \mathrm{~mm}$, while the short cutoff wavelength was $0.025 \mathrm{~mm}$, respectively. The evaluation length was $5 \mathrm{~mm}$ (five sampling lengths). Approximately 150 measuring lines were used, and thus, the mean $R_{a}$ values could be obtained.

2.6.3. Reflectance Measurements. A Shimadzu UV-3101 PC Spectrophotometer (UV-VIS-NIR) was used to gain specimens' reflection spectra in the range of 300-1500 nm.

2.6.4. Gloss Value Measurements. Surface brightness degree was deliberated via the Brightness and Color Meter Model No. 68-50-00-0002.

\subsection{Extract Characterization}

2.7.1. Fourier Transform-Infrared Spectroscopy (FTIR). For FT-IR studies, a Bruker Tensor 37 Fourier transform infrared spectrophotometer instrument was used, and vacuum-dried plant extract liquid was used. The samples were measured by mixing with $\mathrm{KBr}$. The spectra were measured in the range of $400-4000 \mathrm{~cm}^{-1}$.

2.7.2. Gas Chromatography. GC analysis was carried out using a Gas Hewlett Packard HP-5890 series II with split/ split less injector and capillary column $(30 \mathrm{~m}, 0.25 \mathrm{~mm}$, $0.25 \mu \mathrm{m})$ fused with phenyl polysilphenylene siloxane. The injector and detector temperatures were set at 280 and $300^{\circ} \mathrm{C}$, respectively, and the oven temperature was kept at $80^{\circ} \mathrm{C}$ for $1 \mathrm{~min}$, which rose to $300^{\circ} \mathrm{C}$ at $20^{\circ} \mathrm{C} / \mathrm{min}$. Helium was used as carrier gas at a constant flow of $1.0 \mathrm{ml} / \mathrm{min}$. A volume of $2 \mu \mathrm{l}$ was injected in the splitless mode, and the purge time was $1 \mathrm{~min}$.

2.7.3. Gas Chromatography-Mass Spectrometry (GC-MS) Analysis. The MS (Hewlett-Packard 5889 BMS Engine) with selected ion monitoring (SIM) was used; the mass 
spectrometer was operated at $70 \mathrm{eV}$ and scanned fragments from 50 to $650 \mathrm{~m} / \mathrm{z}$.

2.7.4. Identification of Components. The methodology carried out for identification of individual components of plant extract was based on chromatographic retention indices and by comparing the obtained mass spectra with those available in the NIST library.

\section{Results and Discussion}

\subsection{Characterization of Methanolic Plant Extracts}

3.1.1. Fourier Transform-Infrared Spectroscopy (FTIR). FTIR analysis of marjoram, coriander, chamomile, and guava leaves was performed, and the results are shown in Figure 1.

The broad peaks between $3386.04 \mathrm{~cm}^{-1}$ to $3411.62 \mathrm{~cm}^{-1}$ were assigned to the presence of a superficial absorbed water and stretching mode of an (OH). The peaks at 1449, 1409.05, and $1405.54 \mathrm{~cm}^{-1}$ correspond to bending vibration of aliphatic O-H and C-H. The peaks at 877.10, 864.79, 819.49, $819.38,821.77$, and $777.44 \mathrm{~cm}^{-1}$ correspond to bending vibration of $\mathrm{C}-\mathrm{H}$. The peaks at $1694.23 \mathrm{~cm}^{-1}$ are in proportion to stretching vibration of $\mathrm{C}=\mathrm{O}$ of guava leaves extract. The peaks at $1602.59,1607.82,1610.60$, and $1615.07 \mathrm{~cm}^{-1}$ correspond to stretching vibration of $\mathrm{C}=\mathrm{C}$. The peaks at $1040.68 \mathrm{~cm}^{-1}$ correspond to stretching vibration of CO-O$\mathrm{CO}$ of guava leaves extract. The peaks at 1054.06, 1063.11, $1071.04,1262.96,1281.31$, and $1281.95 \mathrm{~cm}^{-1}$ correspond to stretching vibration of $\mathrm{C}-\mathrm{O}$ stretching.

The comparison between the absorbance bands observed by the FTIR spectra of four plant extracts before and after EP is shown in Figure 1. These absorbance bands sometimes appear, disappear, or shift after EP to indicate the formation of a C-steel plant extract complex or salt.

(1) Obviously in marjoram, a strong and broad peak of -OH stretching are observed at $3411.62 \mathrm{~cm}^{-1}$ before EP and are also observed at $3409.83 \mathrm{~cm}^{-1}$ after EP. The stretching peak of $-\mathrm{C}-\mathrm{H}$ is shifted from 2934.31 to $2396.40 \mathrm{~cm}^{-1}$. The stretching peak of $\mathrm{C}=\mathrm{C}$ is shifted from $1607.82 \mathrm{~cm}^{-1}$ to $1636.54 \mathrm{~cm}^{-1}$. The stretching peak of $\mathrm{C}-\mathrm{O}$ shifted from $1071.04 \mathrm{~cm}^{-1}$ to $1023.81 \mathrm{~cm}^{-1}$. Also, the bending peak of $-\mathrm{C}-$ $\mathrm{H}$ shifted from $776.70 \mathrm{~cm}^{-1}$ to 503.89 and $420.22 \mathrm{~cm}^{-1}$. In Guava leaves, the $-\mathrm{C}-\mathrm{H}$ stretching peak is shifted from 2927.69 to $2391.11 \mathrm{~cm}^{-1}$. The $\mathrm{C}=\mathrm{O}$ and $\mathrm{C}-\mathrm{H}$ bands' stretching frequencies are shifted from 1694.3 .5 to 1623.83 $\mathrm{cm}^{-1}$. The $\mathrm{C}=\mathrm{C}$ stretching peak disappeared after $\mathrm{EP}, \mathrm{C}-\mathrm{O}$ from 1283.31 to $1135.51 \mathrm{~cm}^{-1}$, and CO-O-CO from 1040.68 to $1029.04 \mathrm{~cm}^{-1}$. Also, the bending peak of C-H disappeared after EP from $819.38 \mathrm{~cm}^{-1}$ to 908.57 and from 768.88 to 712.95 and $524.97 \mathrm{~cm}^{-1}$. In chamomile, a broad band at $3386.8 \mathrm{~cm}^{-1}$ is attributed to $-\mathrm{OH}$ shifted to $3377.1 \mathrm{~cm}^{-1}$. The C-H stretching peak is shifted from 2932.29 to 2352.07 and $2320.79 \mathrm{~cm}^{-1}$, and the $\mathrm{O}-\mathrm{H}$ bending peak at $1409.00 \mathrm{~cm}^{-1}$ disappeared after EP. The $\mathrm{C}=\mathrm{C}$ stretching peak shifted from 1610.60 to $1626.62 \mathrm{~cm}^{-1}$, C-O from 1281.95 to 1257.72 and from 1063.11 to 1136.74 and $1033.80 \mathrm{~cm}^{-1}$, and $\mathrm{C} \Xi C$ located at $2120.72 \mathrm{~cm}^{-1}$ disappeared after EP. Also, the bending peak of $-\mathrm{C}-\mathrm{H}$ shifted from $777.44 \mathrm{~cm}^{-1}$ to 908.28 and $523.36 \mathrm{~cm}^{-1}$. In coriander, a strong $-\mathrm{OH}$ band at 3408.86 shifted to $3376.59 \mathrm{~cm}^{-1}$, C-H stretching band at 2929.49 is shifted to $2350.69 \mathrm{~cm}^{-1}, \mathrm{C}=\mathrm{C}$ from 1602.59 to $1623.99 \mathrm{~cm}^{-1}$, $\mathrm{O}-\mathrm{H}$ bending peak at $1409.00 \mathrm{~cm}^{-1}$ disappeared after $\mathrm{EP}$, and $\mathrm{C}-\mathrm{O}$ shifted from 1054.06 to 1029.38 and $1131.21 \mathrm{~cm}^{-1}$. Also, the $-\mathrm{C}-\mathrm{H}$ bending peak shifted from $877.10 \mathrm{~cm}^{-1}$ to 907.33, 713.90 and $527.28 \mathrm{~cm}^{-1}$.

The presence and shifted stretching peaks of the functional groups confirm the formation of active compound $-\mathrm{Fe}^{2+}$ complex on the metal surface. Hence, the FTIR spectra show that there is an interaction between the extract and the C-steel substrate which resulted in the retardation effect [10].

3.1.2. $U V$-Visible Spectroscopy. As seen in Figures 2(a)-2(d), the solution having $\mathrm{Fe}^{2+}$ ions exhibit two absorption bands at 209 and $305 \mathrm{~nm}$ in four plants' extract; the guava leaves extract-containing solution shows two bands at 244 and $282 \mathrm{~nm}$, and $\mathrm{Fe}^{2+}$ ions addition to guava leaves extract results in an intense absorption band at $323 \mathrm{~nm}$ indicative of $\mathrm{Fe}$ guava leaves extract complex formation. The marjoram extract-containing solution shows two bands at 292 and $310 \mathrm{~nm} . \mathrm{Fe}^{2+}$ ions addition to marjoram extract results in an intense absorption band at $325 \mathrm{~nm}$ indicative of Fe-marjoram extract complex formation. The coriander seeds extract-containing solution shows two bands at 219 and $309 \mathrm{~nm} . \mathrm{Fe}^{2+}$ ions addition to coriander seeds extract results in two absorption bands at 289 and $316 \mathrm{~nm}$ reflection of Fecoriander extract complex formation. The solution containing chamomile extract shows only one band at $309 \mathrm{~nm}$. $\mathrm{Fe}^{2+}$ ions addition to chamomile extract results in an intense absorption band at $323 \mathrm{~nm}$ investigative of Fe-chamomile extract complex formation.

Fe-plant extract may be as a stable complex adsorbed over the metal surface resulting in retardation influence, or it may be as a soluble complex leading to a catalytic effect. In systems that contain different chemical species, there is a possibility to form both of these two types of complexes. Therefore, the effect of plant extract on the steel dissolution behavior in $8 \mathrm{M} \mathrm{H}_{3} \mathrm{PO}_{4}$ could be interpreted on the basis of two aspects: the retardation influence of the stable complex and other catalytic effect of soluble metal complex. It appears that the retardation influence of the adsorbed metal complex is firstly predominant until a significant concentration where a certain leveling off value of their retardation efficiency is reached. On further increase of the amount of the plant extract, the accelerating effect of other soluble species appears, resulting in a decrease of the maximum retardation efficiency [11]

3.1.3. Gas Chromatography-Mass Spectrometry (GC-MS) Analysis. In the present investigation, 10 organic compounds from marjoram, coriander, chamomile, and guava leaves were identified through GC-MS analysis; Figure 3. The molecular formula, molecular weight, retention time (RT), and probability percentage are presented in Table 1. Among the total compounds, 1-phenanthrenemethanol, 1,2,3,4,4a,9,10,10a-octahydro-1,4a-dimethyl-7-(1- 

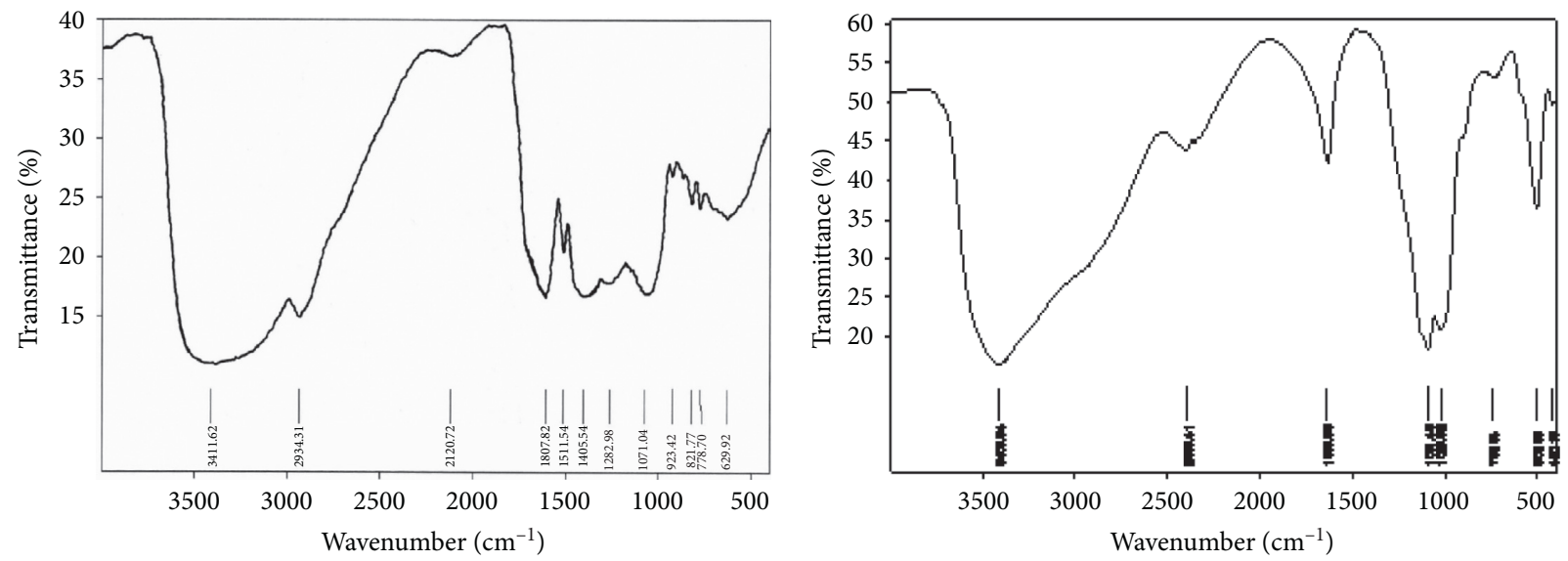

(a)
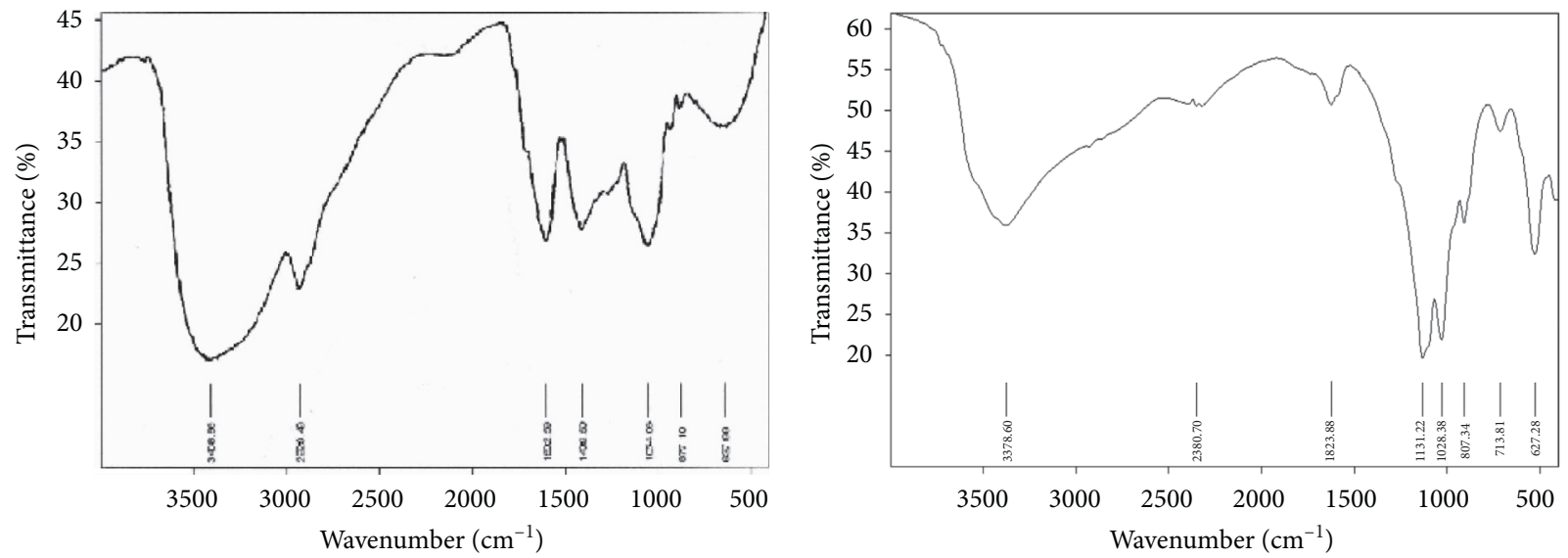

(b)
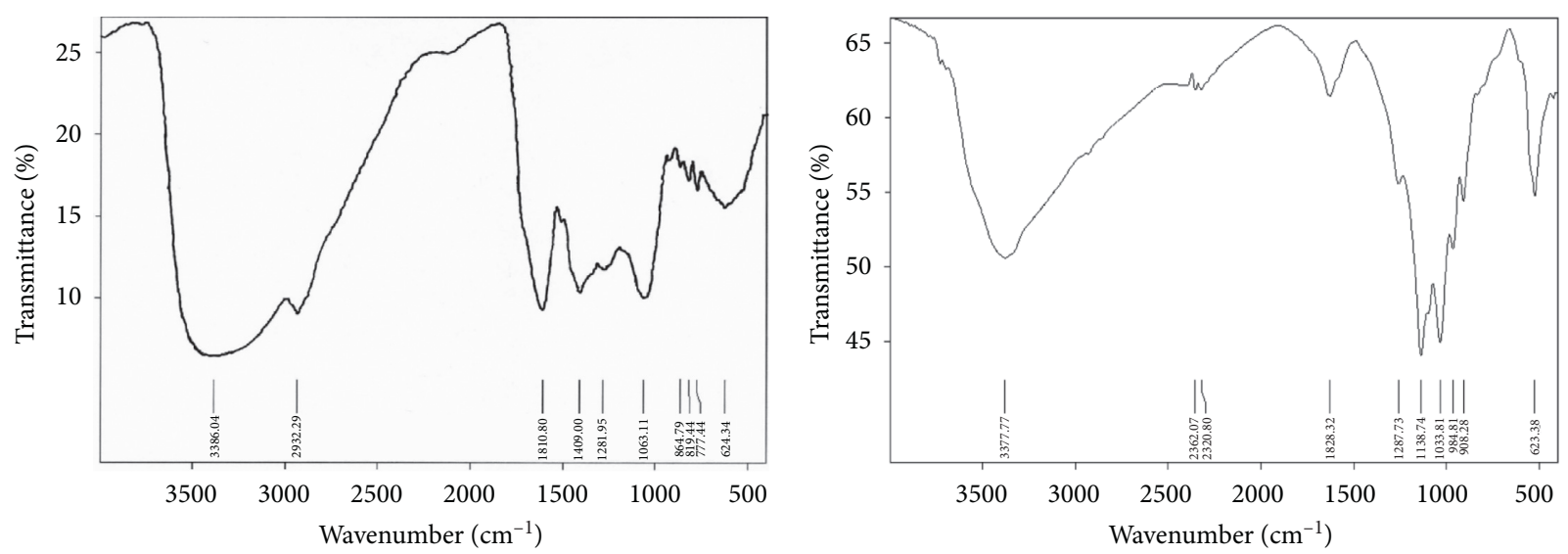

(c)

Figure 1: Continued. 

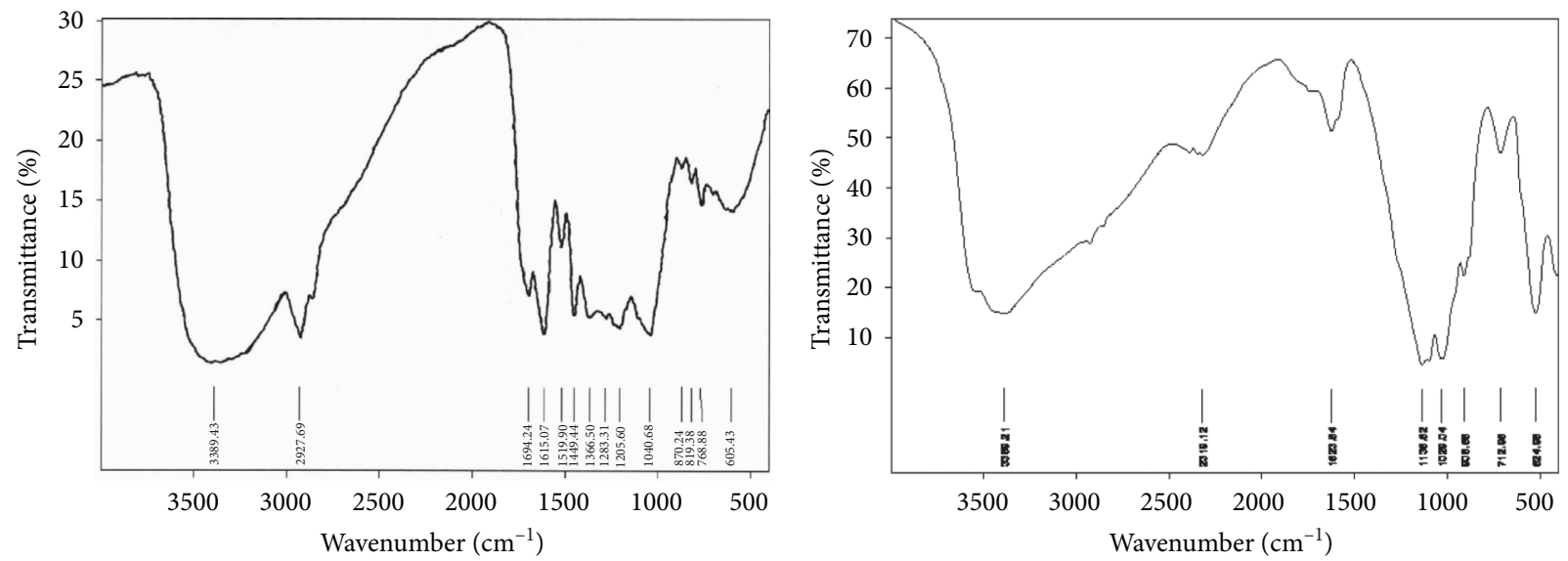

(d)

Figure 1: FTIR spectra of methanolic plant extract.

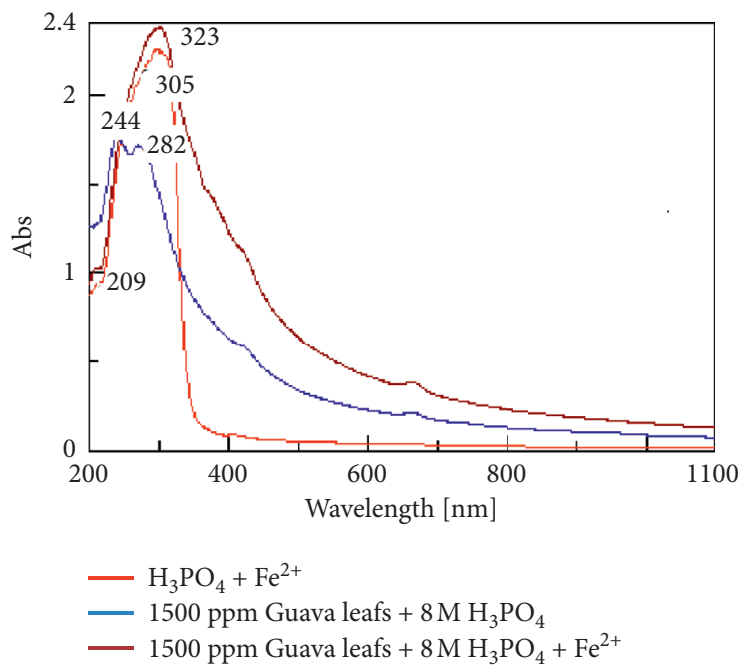

(a)

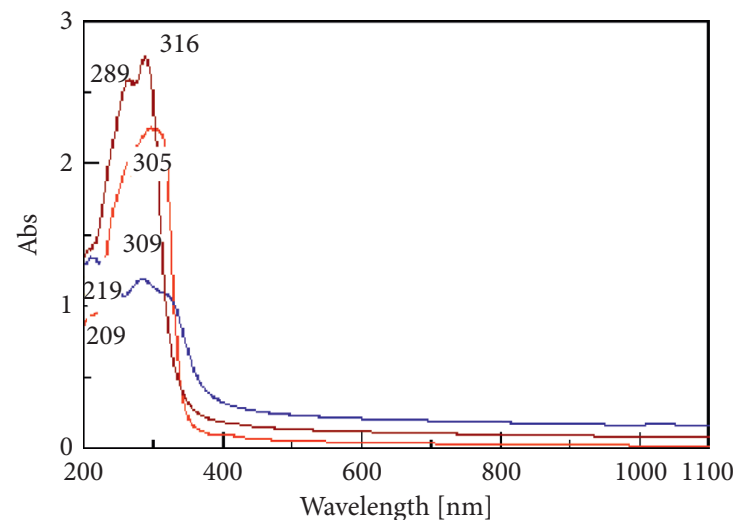

$-\mathrm{H}_{3} \mathrm{PO}_{4}+\mathrm{Fe}^{2+}$

- 1500 ppm Coriander seeds $+8 \mathrm{M} \mathrm{H}_{3} \mathrm{PO}_{4}$

1500 ppm Coriander seeds $+8 \mathrm{M} \mathrm{H}_{3} \mathrm{PO}_{4}+\mathrm{Fe}^{2+}$

(c)

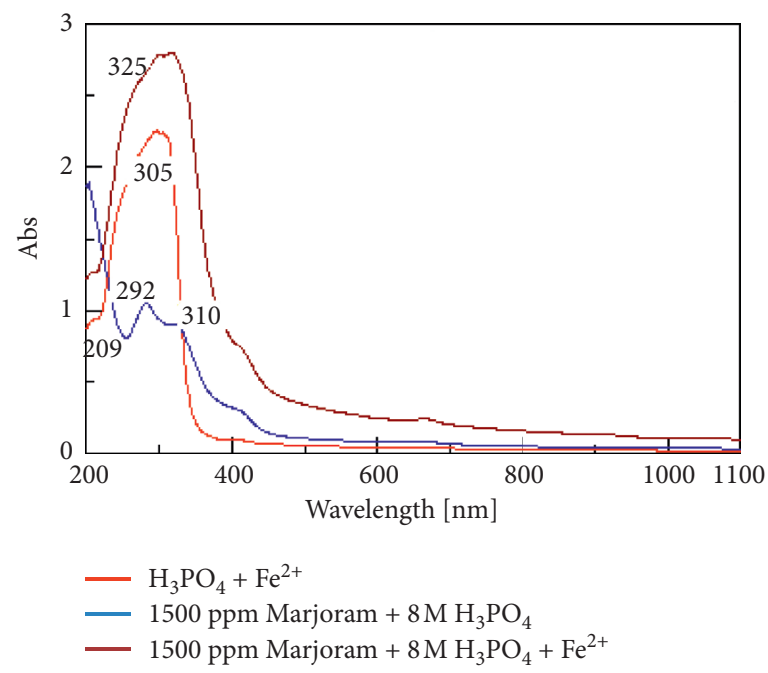

(b)

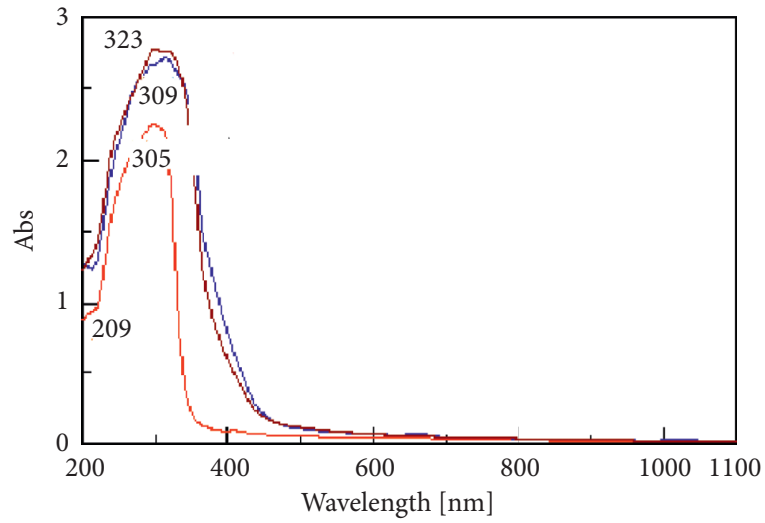

$-\mathrm{H}_{3} \mathrm{PO}_{4}+\mathrm{Fe}^{2+}$

- $1500 \mathrm{ppm}$ Chamomile $+8 \mathrm{M} \mathrm{H}_{3} \mathrm{PO}_{4}$

$-1500 \mathrm{ppm}$ Chamomile $+8 \mathrm{M} \mathrm{H}_{3} \mathrm{PO}_{4}+\mathrm{Fe}^{2+}$

(d)

FIgURE 2: UV-visible spectrum of (a) guava leaves, (b) marjoram, (c) coriander seeds, and (d) chamomile. 


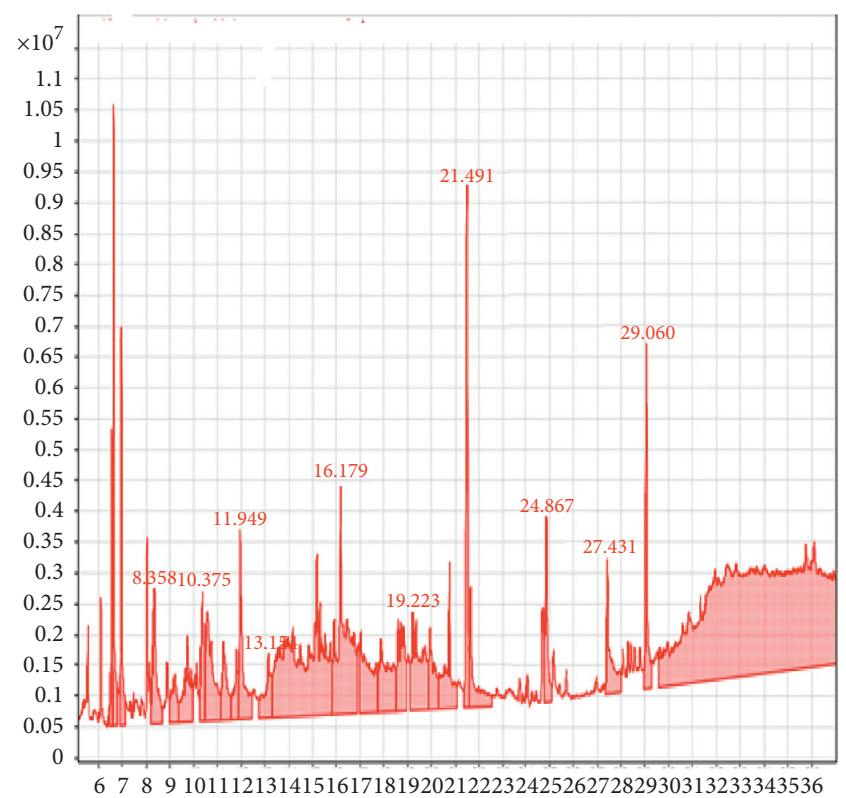

(a)

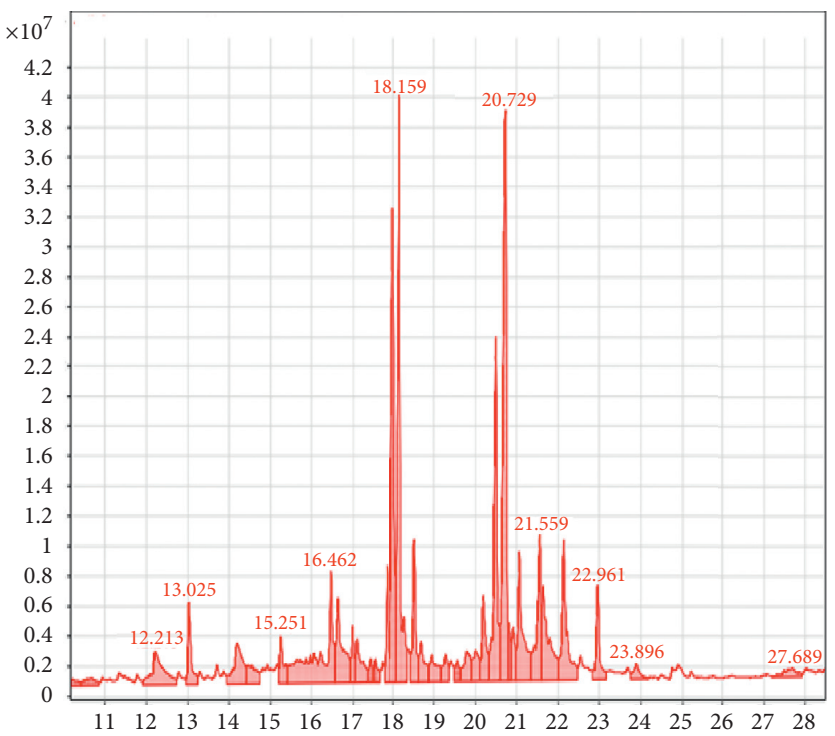

(c)

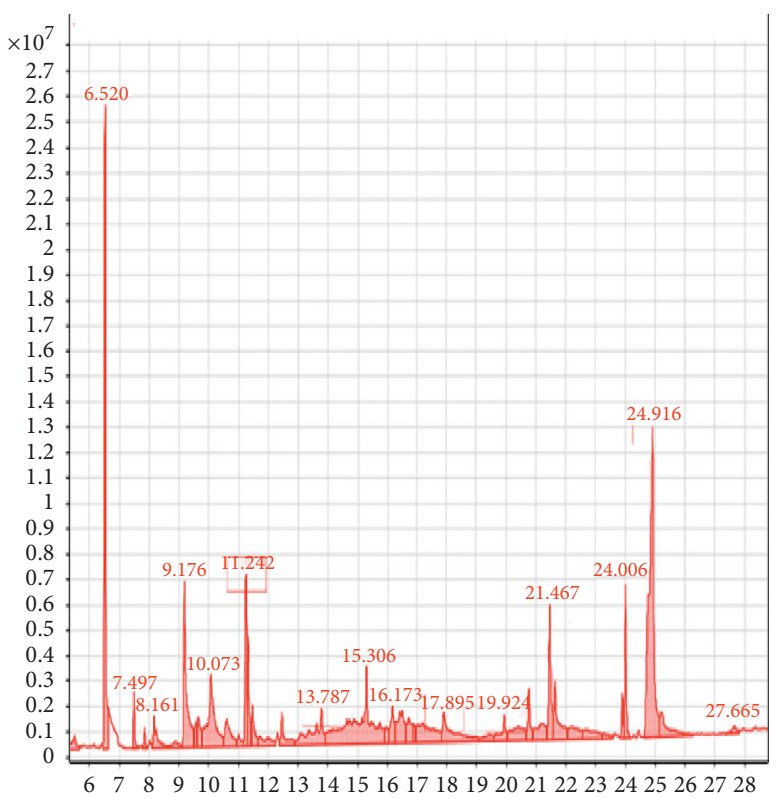

(b)

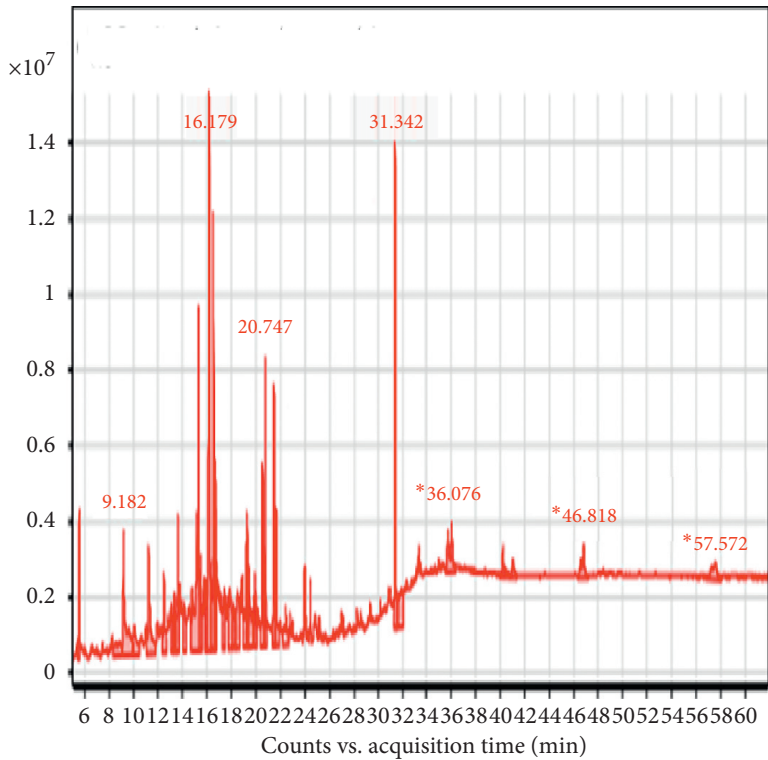

(d)

FIGURE 3: GC-MS spectrum of of methanolic plant extract: (a) marjoram; (b) coriander seeds; (c) chamomile; and (d) guava leaves.

TABLE 1: Some of the chemical components identified in methanolic extract by GC-MS.

\begin{tabular}{|c|c|c|c|c|c|}
\hline No & Identified compound & $\begin{array}{l}\text { Molecular } \\
\text { formula }\end{array}$ & $\begin{array}{l}\text { Molecular } \\
\text { weight }\end{array}$ & RT & Probability \\
\hline \multicolumn{6}{|c|}{ Marjoram } \\
\hline 1 & cis-4-Methoxy thujane & $\mathrm{C}_{11} \mathrm{H}_{20} \mathrm{O}$ & 168 & 6.55 & $75.6 \%$ \\
\hline 2 & Cyclohexanol, 1-methyl-4-(1-methylethenyl)-, cis & $\mathrm{C}_{10} \mathrm{H}_{18} \mathrm{O}$ & 154 & 6.64 & $45.5 \%$ \\
\hline 3 & trans-4-Methoxy thujane & $\mathrm{C}_{11} \mathrm{H}_{20} \mathrm{O}$ & 168 & 6.96 & $38.3 \%$ \\
\hline 4 & Methyleugenol & $\mathrm{C}_{11} \mathrm{H}_{14} \mathrm{O}_{2}$ & 178 & 11.94 & $33.0 \%$ \\
\hline 5 & $\begin{array}{l}\text { 1H-cycloprop[e]azulen-7-ol, decahydro-1,1,7-trimethyl-4-methylene-, [1ar- } \\
\qquad(1 \mathrm{a} \alpha, 4 \mathrm{a} \alpha, 7 \beta, 7 \mathrm{a} \beta, 7 \mathrm{~b} \alpha)]\end{array}$ & $\mathrm{C}_{15} \mathrm{H}_{24} \mathrm{O}$ & 220 & 15.18 & $12.3 \%$ \\
\hline 6 & $\alpha$-Acorenol & $\mathrm{C}_{15} \mathrm{H}_{26} \mathrm{O}$ & 222 & 16.18 & $7.30 \%$ \\
\hline 7 & Oxiraneundecanoic acid, 3-pentyl-, methyl ester, cis & $\mathrm{C}_{19} \mathrm{H}_{36} \mathrm{O}_{3}$ & 312 & 20.76 & $12.9 \%$ \\
\hline 8 & n-Hexadecanoic acid & $\mathrm{C}_{16} \mathrm{H}_{32} \mathrm{O}_{2}$ & 256 & 21.49 & $64.2 \%$ \\
\hline
\end{tabular}


TABLE 1: Continued.

\begin{tabular}{|c|c|c|c|c|c|}
\hline No & Identified compound & $\begin{array}{l}\text { Molecular } \\
\text { formula }\end{array}$ & $\begin{array}{l}\text { Molecular } \\
\text { weight }\end{array}$ & RT & Probability \\
\hline 9 & $9,12,15$-Octadecatrienoic acid, $(\mathrm{Z}, \mathrm{Z}, \mathrm{Z})$ & $\mathrm{C}_{18} \mathrm{H}_{30} \mathrm{O}_{2}$ & 278 & 24.86 & $12.2 \%$ \\
\hline 10 & 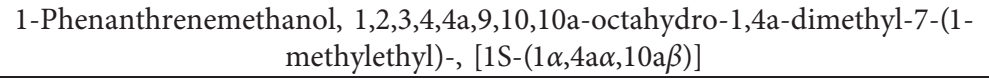 & $\mathrm{C}_{20} \mathrm{H}_{30} \mathrm{O}$ & 286 & 29.06 & $15.0 \%$ \\
\hline \multicolumn{6}{|c|}{ Coriander seeds } \\
\hline 1 & 1,6-Octadien-3-ol, 3,7-dimethyl & $\mathrm{C}_{10} \mathrm{H}_{18} \mathrm{O}$ & 154 & 6.52 & $76.1 \%$ \\
\hline 2 & Benzaldehyde, 4-(1-methylethyl) & $\mathrm{C}_{10} \mathrm{H}_{12} \mathrm{O}$ & 148 & 9.21 & $33.9 \%$ \\
\hline 3 & p-Cymen-7-ol & $\mathrm{C}_{10} \mathrm{H}_{14} \mathrm{O}$ & 150 & 10.07 & $58.6 \%$ \\
\hline 4 & Eugenol & $\mathrm{C}_{10} \mathrm{H}_{12} \mathrm{O}_{2}$ & 164 & 11.24 & $20.8 \%$ \\
\hline 5 & 3-Allyl-6-methoxyphenol & $\mathrm{C}_{10} \mathrm{H}_{12} \mathrm{O}_{2}$ & 164 & 11.32 & $12.7 \%$ \\
\hline 6 & Caryophyllene oxide & $\mathrm{C}_{15} \mathrm{H}_{24} \mathrm{O}$ & 220 & 15.30 & $28.7 \%$ \\
\hline 7 & n-Hexadecanoic acid & $\mathrm{C}_{16} \mathrm{H}_{32} \mathrm{O}_{2}$ & 256 & 21.47 & $65.9 \%$ \\
\hline 8 & 6-Octadecenoic acid, methyl ester, (Z) & $\mathrm{C}_{19} \mathrm{H}_{36} \mathrm{O}_{2}$ & 296 & 24.00 & $12.3 \%$ \\
\hline 9 & cis-Vaccenic acid & $\mathrm{C}_{18} \mathrm{H}_{34} \mathrm{O}_{2}$ & 282 & 24.91 & $15.1 \%$ \\
\hline 10 & Oleic Acid & $\mathrm{C}_{18} \mathrm{H}_{34} \mathrm{O}_{2}$ & 282 & 33.27 & $14.5 \%$ \\
\hline \multicolumn{6}{|c|}{ Chamomile } \\
\hline 1 & $\begin{array}{l}\text { 2-Furanmethanol, tetrahydro- } \alpha, \alpha, 5 \text {-trimethyl-5-(4-methyl-3-cyclohexen-1- } \\
\text { yl)-, }\left[2 S-\left[2 \alpha, 5 \beta\left(\mathrm{R}^{*}\right)\right]\right]\end{array}$ & $\mathrm{C}_{15} \mathrm{H}_{26} \mathrm{O}_{2}$ & 238 & 16.46 & $53.4 \%$ \\
\hline 2 & 11,13-Dihydroxy-tetradec-5-ynoic acid, methyl ester & $\mathrm{C}_{15} \mathrm{H}_{26} \mathrm{O}_{4}$ & 270 & 17.83 & $32.3 \%$ \\
\hline 3 & 2H-1-Benzopyran-2-one, 7-methoxy & $\mathrm{C}_{10} \mathrm{H}_{8} \mathrm{O}_{3}$ & 176 & 18.01 & $92.5 \%$ \\
\hline 4 & $\begin{array}{l}\text { 2H-Pyran-3-ol, tetrahydro-2,2,6-trimethyl-6-(4-methyl-3-cyclohexen-1-yl)-, } \\
\left.\qquad 3 \mathrm{~S}-\left[3 \alpha, 6 \alpha\left(\mathrm{R}^{*}\right)\right]\right]\end{array}$ & $\mathrm{C}_{15} \mathrm{H}_{26} \mathrm{O}_{2}$ & 238 & 18.16 & $85.6 \%$ \\
\hline 5 & Limonen-6-ol, pivalate & $\mathrm{C}_{15} \mathrm{H}_{24} \mathrm{O}_{2}$ & 236 & 18.52 & $11.0 \%$ \\
\hline 6 & 1,6-Dioxaspiro[4.4]non-3-ene, 2-(2,4-hexadiynylidene) & $\mathrm{C}_{13} \mathrm{H}_{12} \mathrm{O}_{2}$ & 200 & 20.50 & $83.5 \%$ \\
\hline 7 & Anthracene, $1,2,3,4,5,6,7,8$-octahydro-1-methyl & $\mathrm{C}_{15} \mathrm{H}_{2} \mathrm{O}$ & 200 & 20.73 & $3.06 \%$ \\
\hline 8 & Formic acid, 3,7,11-trimethyl-1,6,10-dodecatrien-3-yl ester & $\mathrm{C}_{16} \mathrm{H}_{26} \mathrm{O}_{2}$ & 250 & 21.07 & $10.1 \%$ \\
\hline 9 & n-Hexadecanoic acid & $\mathrm{C}_{16} \mathrm{H}_{32} \mathrm{O}_{2}$ & 256 & 21.56 & $52.1 \%$ \\
\hline 10 & $\begin{array}{l}\text { 5-Hydroxymethyl-1,3,3-trimethyl-2-(3-methyl-buta-1,3-dienyl)- } \\
\text { cyclopentanol }\end{array}$ & $\mathrm{C}_{14} \mathrm{H}_{24} \mathrm{O}_{2}$ & 224 & 22.15 & $4.00 \%$ \\
\hline \multicolumn{6}{|c|}{ Guava leaves } \\
\hline 1 & Benzaldehyde, 4-(1-methylethyl) & $\mathrm{C}_{10} \mathrm{H}_{12} \mathrm{O}$ & 148 & 9.18 & $41.3 \%$ \\
\hline 2 & Caryophyllene oxide & $\mathrm{C}_{15} \mathrm{H}_{24} \mathrm{O}$ & 220 & 15.31 & $47.5 \%$ \\
\hline 3 & Tetracyclo[6.3.2.0(2,5).0(1,8)]tridecan-9-ol, 4,4-dimethyl & $\mathrm{C}_{15} \mathrm{H}_{24} \mathrm{O}$ & 220 & 16.18 & $51.6 \%$ \\
\hline 4 & Globulol & $\mathrm{C}_{15} \mathrm{H}_{26} \mathrm{O}$ & 222 & 16.51 & $9.92 \%$ \\
\hline 5 & 9-Hexadecenoic acid & $\mathrm{C}_{16} \mathrm{H}_{30} \mathrm{O} 2$ & 254 & 16.67 & $8.95 \%$ \\
\hline 6 & Isoaromadendrene epoxide & $\mathrm{C}_{15} \mathrm{H}_{24} \mathrm{O}$ & 220 & 16.72 & $12.7 \%$ \\
\hline 7 & 4,4,8-Trimethyltricyclo[6.3.1.0(1,5)]dodecane-2,9-diol & $\mathrm{C}_{15} \mathrm{H}_{26} \mathrm{O}_{2}$ & 238 & 20.53 & $74.4 \%$ \\
\hline 8 & Hexadecanoic acid, methyl ester & $\mathrm{C}_{17} \mathrm{H}_{34} \mathrm{O}_{2}$ & 270 & 20.74 & $23.7 \%$ \\
\hline 10 & Diisooctyl phthalate & $\mathrm{C}_{24} \mathrm{H}_{38} \mathrm{O}_{4}$ & 390 & 31.34 & $18.5 \%$ \\
\hline
\end{tabular}

methylethyl)-, [1S-(1 $\alpha, 4 \mathrm{a} \alpha, 10 \mathrm{a} \beta)]$ (RT 29.06) was the major compound identified in the marjoram extract, cis-vaccenic acid (RT 24.91 was the major compound identified in the coriander seed extract, anthracene, 1,2,3,4,5,6,7,8-octahydro-1-methyl (RT 20.729) was the major compound identified in the chamomile seed extract, and diisooctyl phthalate (RT 31.43) was the major compound identified in the guava leaves extract.

3.2. Leveling Process. An atypical polarization curve is obtained for an electrolyte consisting of $\mathrm{H}_{3} \mathrm{PO}_{4}$ of concentrations ranged from $6 \mathrm{M}$ to $14 \mathrm{M}$. Figure 4 is divided into three parts which are electrolytic etching, polishing, and $\left(\mathrm{O}_{2}\right)$ evolution that occurred consequently with the metal dissolution process The influence of $\mathrm{H}_{3} \mathrm{PO}_{4}$ concentration on the value of $I_{L}$ can be explicated based on the mass transfer equation $[12,13]$.

$$
\mathrm{I}_{\mathrm{L}}=\frac{\mathrm{nZFD}}{\boldsymbol{\delta}} \mathrm{C}_{\mathrm{Fe}^{3+}}
$$

$\mathbf{I}_{\mathrm{L}}=$ limiting current (A); $\mathbf{Z}=$ working area $\left(\mathrm{cm}^{2}\right)$; $n=$ charge of the ion involved; $\mathbf{F}=$ Faraday constant (A.s. $\left.\mathrm{mol}^{-1}\right) ; \mathbf{D}=$ diffusion coefficient of the rate-limiting species $\left(\mathrm{cm}^{2} \cdot \mathrm{s}^{-1}\right) ; \mathbf{C}_{\mathrm{Fe}^{+3}}=$ saturation concentration of iron $\left(\mathrm{mol} . \mathrm{L}^{-1}\right)$ of metal ions $\left(\mathrm{Fe}^{+3}\right)$ in the solution for the salt film mechanism or bulk $\mathbf{C}$ of the acceptor species for acceptor mechanism; and $d=$ thickness of the Nernst diffusion layer $(\mathrm{cm})$.

Increasing orthophoshoric acid concentration leads to decreas in the saturation solubility of $\mathrm{FePO}_{4}$, increase in viscosity $(\mu)$ of the solution (which leads to reduce $\mathrm{Fe}^{3+}$ ions diffusivity $(D)$ consistent with the Stokes-Einstein equation 


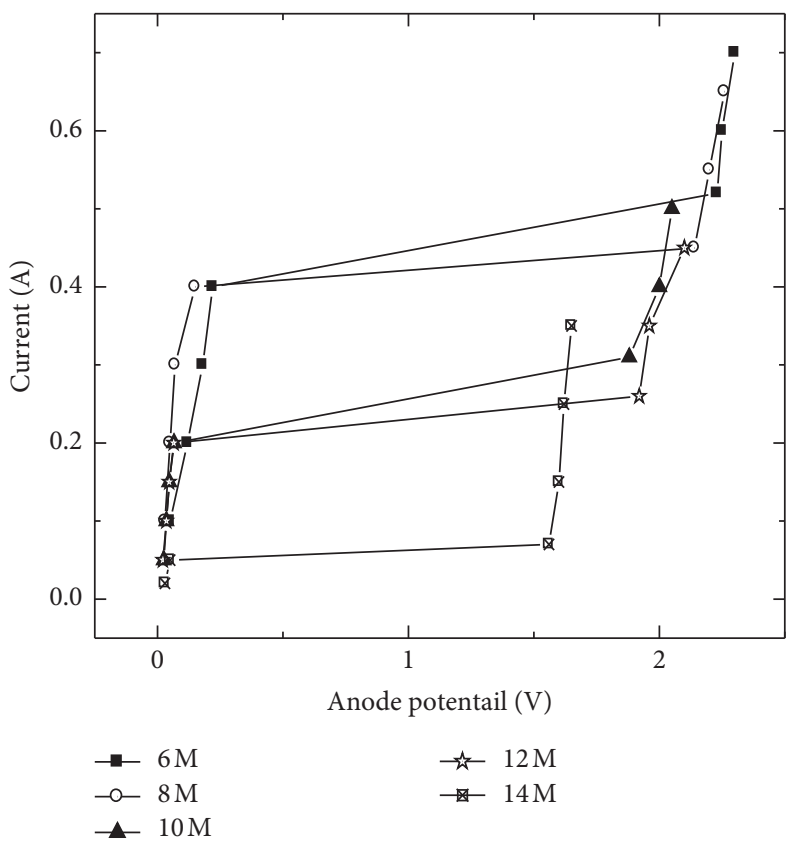

Figure 4: Typical polarization curve for carbon steel electropolishing at $20^{\circ} \mathrm{C}$ in the presence of different concentrations of $\mathrm{H}_{3} \mathrm{PO}_{4}$ acid.

$\mathbf{D} \eta / \mathbf{T}=$ constant), and an augment in the diffusion layer thickness $(\delta)$ (which signifies the rate of mass transfer of $\mathrm{Fe}^{3+}$ ions the resistance from the anode surface to the solution bulk. Due to these effects, $\mathbf{I}_{\mathbf{L}}$ decreases with increasing $\mathrm{H}_{3} \mathrm{PO}_{4}$ concentration).

During EP of iron in $\mathrm{H}_{3} \mathrm{PO}_{4}$ (Figure 4), when current passes across the electrolyte, the anode surface is coated with a thick film. This layer has elevated viscosity and electrical resistivity than the solution bulk. The layer breadth vary from spot to spot: over projections, the layer is thinner than over the valleys. Therefore, climaxes dissolve first followed by valleys. Also, the metal salt out diffusion is slow in comparison with that over a peak. The nonuniform current density metal from projections dissolves more rapidly than from crevices which results in a surface leveling influence. Thus, $\mathbf{I}_{\mathbf{L}}$ behavior is due to the fact that the dissolution is under mass transport control [14], in which reaction products diffusion is limited and is, in turn, determining the overall reaction rate. The salt-film precipitated mechanism involves rate-limiting diffusion of cations of the dissolving metal from the anode into the bulk [15]. At $\mathbf{I}_{\mathrm{L}}$, a skinny salt film with a saturated concentration of the metallic cation is present on the anode surface and limits the rate at which metal ions depart the surface.

The curves showed the typical I-V uniqueness for EP, where three regions corresponding to pitting, polishing, and gas evolution on the anode surface were identified depending upon the potential applied. Initially, the current linearly increased from the starting of the potential scan and reaches a plateau. This action is dictated by the ohmic resistance in the electrolyte. At higher potential, the fluctuation of both current and potential found, and over the horizontal range, the current remains constant although the potential amplifies.
Anodic dissolution of C-steel in $\mathrm{H}_{3} \mathrm{PO}_{4}$ shows a limiting current plateau. In the potential range below $\mathrm{I}_{\mathrm{L}}$, C-steel dissolution occupies concurrent $\mathrm{Fe}^{2+}$ and $\mathrm{Fe}^{3+}$ formation, $\mathrm{Fe}^{3+}$ formation amount becoming significant at superior potential. In the potential range corresponding to the limiting current plateau, C-steel dissolution results in $\mathrm{Fe}^{3+}$ formation only. At potentials elevated than $\mathrm{I}_{\mathrm{L}}, \mathrm{O}_{2}$ evolution at C-steel anode dissolution will appear.

3.3. Electropolishing of C-Steel in $\mathrm{H}_{3} \mathrm{PO}_{4}$ with Natural Products. Figure 5 Demonstrates polarization curves for C-steel anodic dissolution in $\mathrm{H}_{3} \mathrm{PO}_{4}$ containing various concentrations of marjoram, coriander seeds, chamomile, and guava leaves methanolic extract, respectively.

The current was plotted against the applied potential, and the linear portion, an extrapolation of the dissolution potential, gives the limiting current $\left(\mathbf{I}_{\mathbf{L}}\right) . \mathbf{I}_{\mathbf{L}}$ values are given in Table 2.

Appearance of a limiting current plateau in the solution containing several extract concentrations shows that the extracts do not alter the diffusion-controlled mechanism for iron dissolution to a charge transfer mechanism. However, the plant extracts affect the $\mathbf{I}_{\mathbf{L}}$ by diverse extent reflecting their retardation influence which is dependant on the plant extract type.

If $\mathrm{I}_{\mathrm{L} \text { (blank) }}$ is the limiting current in $8 \mathrm{M} \mathrm{H}_{3} \mathrm{PO}_{4}$-free solution and $\mathrm{I}_{\mathrm{L} \text { (extract) }}$ is the limiting current in $8 \mathrm{M} \mathrm{H}_{3} \mathrm{PO}_{4}$ containing plant extract, then the inhibition efficiency percentage (\%IE) can be calculated as follows:

$$
\% I E=\frac{\left(I_{L(\text { blank })}-I_{L(\text { extract })}\right)}{I_{L(\text { blank })}} \times 100 .
$$




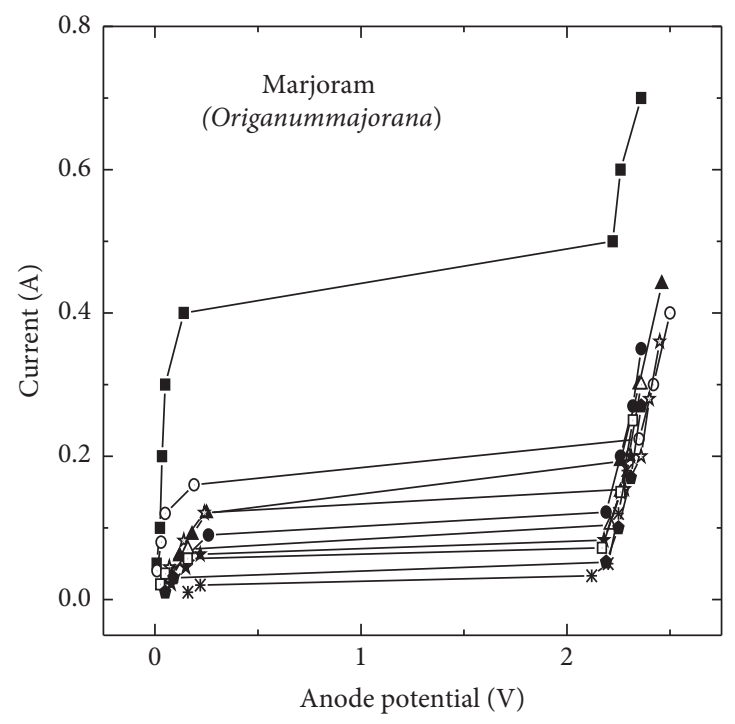

Conc. $(\mathrm{ppm})$
-0.0
$\multimap-100$
$\leftarrow 200$
$\leftarrow 300$

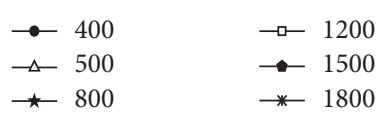

(a)

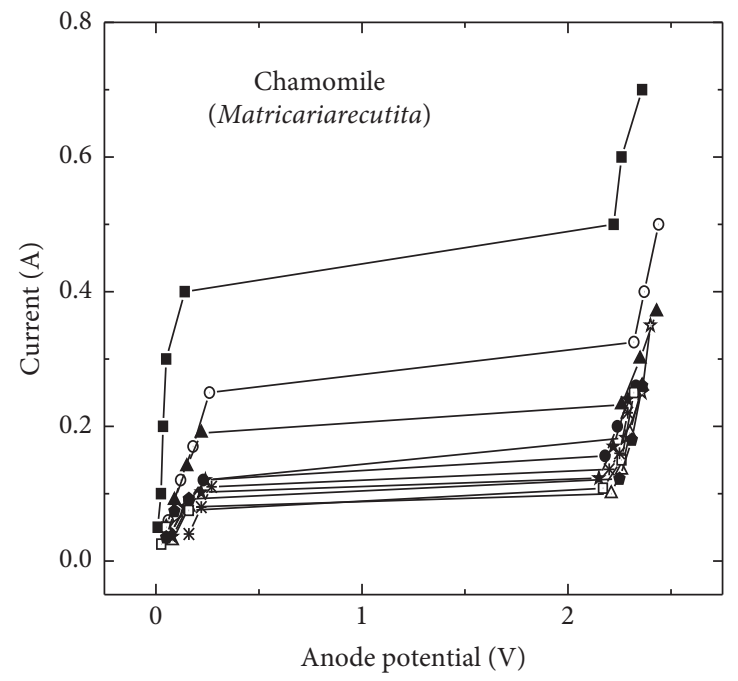

Conc. (ppm)
-0.0
-100
-200
$\approx \quad 300$

$\rightarrow 400$

$\triangle-500$

$\star 800$

(c)
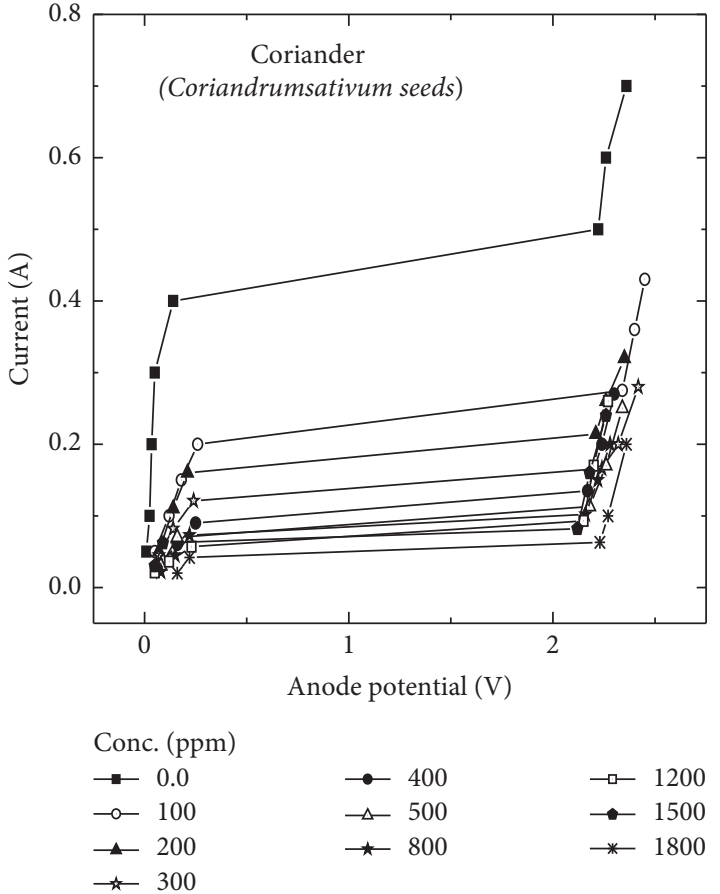

(b)

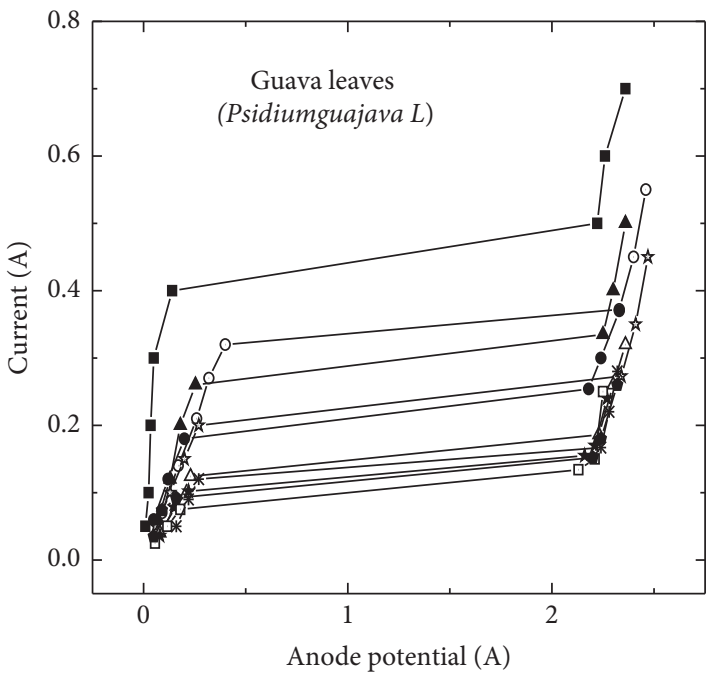

Conc. $(\mathrm{ppm})$
-0.0
--100
$\simeq 200$
$\longleftarrow \quad 300$

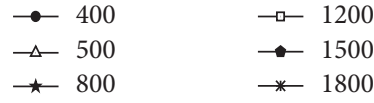

(d)

Figure 5: Characteristic polarization curve for C-steel electropolishing in $8 \mathrm{M} \mathrm{H}_{3} \mathrm{PO}_{4}$ containing several concentrations of (a) marjoram, (b) coriander seeds, (c) chamomile, and (d) guava leaves at $25 \mathrm{C}$.

The anodic dissolution rate $\mathbf{I}_{\mathbf{L}}$ values and percentage inhibition efficiency (\%IE) for the studied plant extract at a concentration range from 50 to 1800 and temperature range of $25-55^{\circ} \mathrm{C}$ with an increment of $10^{\circ} \mathrm{C}$ are given in Table 2 .

Table 2 shows that \%IE increases as the studied methanolic extracts increase and temperature decreases (except guava leaves). The $\%$ IE of different methanolic extracts could be arranged in the order as follows: Marjoram $>$ Coriander $>$ Chamomile $>$ Guava leaves.

The order imitates the significant function played via the molecular size and the substituent group, as well as functional adsorption atom type, in the retardation processes.

The retardation efficiency of the studied plant extracts was found to be increasing from $50-1800 \mathrm{ppm}$ extract 
TABLE 2: Limiting current values for C-steel dissolution in $8 \mathrm{M} \mathrm{H}_{3} \mathrm{PO}_{4}$ acid in the absence and presence of natural extracts at several temperatures.

\begin{tabular}{|c|c|c|c|c|c|c|c|c|c|}
\hline \multirow{2}{*}{ Natural compound } & \multirow{2}{*}{ Conc. (ppm) } & \multicolumn{2}{|c|}{$25^{\circ} \mathrm{C}$} & \multicolumn{2}{|c|}{$35^{\circ} \mathrm{C}$} & \multicolumn{2}{|c|}{$45^{\circ} \mathrm{C}$} & \multicolumn{2}{|c|}{$55^{\circ} \mathrm{C}$} \\
\hline & & $\mathrm{I}_{\mathrm{L}}(\mathrm{A})$ & IE $\%$ & $\mathrm{I}_{\mathrm{L}}(\mathrm{A})$ & IE\% & $\mathbf{I}_{\mathrm{L}}(\mathrm{A})$ & IE\% & $\mathrm{I}_{\mathrm{L}}(\mathrm{A})$ & IE\% \\
\hline \multirow{10}{*}{ Marjoram (Origanum majorana) } & 0.00 & 0.500 & & 0.560 & & 0.670 & & 0.750 & \\
\hline & 100 & 0.224 & 55.2 & 0.30 & 46.43 & 0.366 & 45.36 & 0.49 & 34.67 \\
\hline & 200 & 0.193 & 61.4 & 0.245 & 56.25 & 0.302 & 54.93 & 0.43 & 42.67 \\
\hline & 300 & 0.154 & 69.2 & 0.194 & 65.36 & 0.262 & 60.90 & 0.321 & 57.20 \\
\hline & 400 & 0.122 & 75.6 & 0.166 & 70.36 & 0.243 & 63.73 & 0.283 & 62.27 \\
\hline & 500 & 0.104 & 79.2 & 0.142 & 74.64 & 0.203 & 69.70 & 0.262 & 65.07 \\
\hline & 800 & 0.083 & 83.4 & 0.122 & 78.21 & 0.176 & 73.73 & 0.241 & 67.87 \\
\hline & 1200 & 0.072 & 85.6 & 0.105 & 81.25 & 0.156 & 76.72 & 0.223 & 70.27 \\
\hline & 1500 & 0.052 & 89.6 & 0.088 & 84.29 & 0.132 & 80.30 & 0.193 & 74.27 \\
\hline & 1800 & 0.033 & 93.4 & 0.065 & 88.39 & 0.103 & 84.63 & 0.167 & 77.73 \\
\hline \multirow{10}{*}{ Coriander (Coriandrum sativum) seeds } & 0.00 & 0.500 & & 0.560 & & 0.670 & & 0.750 & \\
\hline & 100 & 0.275 & 45.0 & 0.333 & 40.54 & 0.440 & 34.33 & 0.525 & 30.00 \\
\hline & 200 & 0.214 & 57.2 & 0.278 & 50.36 & 0.365 & 45.52 & 0.465 & 38.00 \\
\hline & 300 & 0.166 & 66.8 & 0.223 & 60.18 & 0.306 & 54.33 & 0.378 & 49.60 \\
\hline & 400 & 0.135 & 73.0 & 0.221 & 60.54 & 0.276 & 58.81 & 0.322 & 57.07 \\
\hline & 500 & 0.113 & 77.4 & 0.186 & 66.79 & 0.245 & 63.43 & 0.281 & 62.53 \\
\hline & 800 & 0.102 & 79.6 & 0.162 & 71.07 & 0.213 & 68.21 & 0.263 & 64.93 \\
\hline & 1200 & 0.093 & 81.4 & 0.143 & 74.46 & 0.184 & 72.54 & 0.243 & 67.60 \\
\hline & 1500 & 0.082 & 83.6 & 0.125 & 77.68 & 0.162 & 75.82 & 0.223 & 70.27 \\
\hline & 1800 & 0.062 & 87.6 & 0.096 & 82.86 & 0.142 & 78.81 & 0.204 & 72.80 \\
\hline \multirow{10}{*}{ Chamomile (Matricaria recutita) } & 0.00 & 0.500 & & 0.560 & & 0.670 & & 0.750 & \\
\hline & 100 & 0.325 & 35.0 & 0.378 & 32.50 & 0.463 & 30.90 & 0.543 & 27.60 \\
\hline & 200 & 0.232 & 53.6 & 0.305 & 45.54 & 0.375 & 44.03 & 0.502 & 33.07 \\
\hline & 300 & 0.183 & 63.4 & 0.265 & 52.68 & 0.322 & 51.94 & 0.445 & 40.67 \\
\hline & 400 & 0.156 & 68.8 & 0.242 & 56.79 & 0.292 & 56.42 & 0.402 & 46.40 \\
\hline & 500 & 0.135 & 73.0 & 0.209 & 62.68 & 0.262 & 60.90 & 0.364 & 51.47 \\
\hline & 800 & 0.123 & 75.4 & 0.189 & 66.25 & 0.242 & 63.88 & 0.315 & 58.00 \\
\hline & 1200 & 0.108 & 78.4 & 0.165 & 70.54 & 0.212 & 68.36 & 0.278 & 62.93 \\
\hline & 1500 & 0.122 & 75.6 & 0.176 & 68.57 & 0.225 & 66.42 & 0.302 & 59.73 \\
\hline & 1800 & 0.136 & 72.8 & 0.206 & 63.21 & 0.258 & 61.49 & 0.335 & 55.33 \\
\hline \multirow{10}{*}{ Guava leaves (Psidium guajava L) } & 0.00 & 0.500 & & 0.560 & & 0.670 & & 0.750 & \\
\hline & 100 & 0.372 & 25.6 & 0.405 & 28.21 & 0.502 & 25.07 & 0.572 & 23.73 \\
\hline & 200 & 0.335 & 33.0 & 0.362 & 35.68 & 0.445 & 33.58 & 0.543 & 27.60 \\
\hline & 300 & 0.273 & 45.4 & 0.322 & 42.50 & 0.387 & 42.24 & 0.502 & 33.07 \\
\hline & 400 & 0.254 & 49.2 & 0.296 & 47.14 & 0.362 & 45.97 & 0.456 & 39.20 \\
\hline & 500 & 0.186 & 62.8 & 0.242 & 56.79 & 0.333 & 50.30 & 0.425 & 43.33 \\
\hline & 800 & 0.155 & 69.0 & 0.225 & 59.82 & 0.306 & 54.33 & 0.387 & 48.40 \\
\hline & 1200 & 0.134 & 73.2 & 0.203 & 63.75 & 0.283 & 57.76 & 0.342 & 54.40 \\
\hline & 1500 & 0.152 & 69.6 & 0.228 & 59.29 & 0.318 & 52.54 & 0.366 & 51.20 \\
\hline & 1800 & 0.167 & 66.6 & 0.253 & 54.82 & 0.345 & 51.49 & 0.393 & 47.60 \\
\hline
\end{tabular}

concentration. A maximum of chamomile and guava leaves \%IE has been exhibited at $1200 \mathrm{ppm}$. However, it is observed that the behavior is there after overturned with augment in the chamomile and guava leaves concentration (at 1500 and 1800 ppm).

They have an optimum concentration (1200) after which $\mathbf{I}_{\mathbf{L}}$ increases and \%IE decreases. The increase in \%IE could be featured to the chemical ingredients adsorption of methanolic extracts of the studied natural products.

The effect of chamomile and guava leaves on the anodic dissolution behavior of C-steel in $8 \mathrm{M} \mathrm{H}_{3} \mathrm{PO}_{4}$ could be interpreted on the basis of two aspects:
(1) The retardation effect of the stable metal complex adsorbed over the metal surface

(2) Catalytic effect of the soluble metal complex

Since chamomile and guava leaves extracts are rich in compounds such as alkaloids, flavonoids, and tannins, there is an opportunity to form both the complexes types. Consequently, their retardation influence could be explained on the basis of the two factors. It seems that inhibitive effect of the adsorbed metal complex is firstly major until optimum concentration where a confident leveling-off value of their retardation is reached. After a certain period, on further 
increasing the plant extract amount, the accelerating effect of soluble metal complexes appears, leading to diminishing of the greatest retardation efficiency as in the case of chamomile and guava leaves $[11,16,17]$.

On additional examination of Table 2, it is monitored that methanolic extract of marjoram leads to decrease in the anodic dissolution rate $\left(\mathbf{I}_{\mathbf{L}}\right.$ values) of C-steel and increase in the value of \%IE up to $1800 \mathrm{ppm}$. The dissolution retardation can be featured to the main component adsorption of marjoram (cis- and tarns-sabiene hydrate, thymol, and ethyl eugenal) on the C-steel surface. Due to the extract complex chemical composition, it is relatively tricky to allocate the retardation influence to a scrupulous component. However, communal influences of these constituent and others present in the extract cannot be ruled out. The structures of the compounds in Table 1 show that there is an abundance of $\mathrm{O}-\mathrm{H}, \mathrm{C}=\mathrm{O}, \mathrm{C}-\mathrm{O}$, and $-\mathrm{CH}_{3}$ along with aromatic rings. This reality has been proved through the corresponding peaks in the FTIR (Figure 1). Therefore, it is reasonable to declare that the marjoram extract efficacy against $\mathrm{C}$-steel dissolution belongs to the successful chemical constituent adsorption [18].

Methanolic extract of coriander seeds is composed of numerous naturally occurring compounds which may react with the iron, first dissolved from the metal surface, forming an organometal complex such as Fe-plant extract [Fe-PE] according to the following mechanism [19]

$$
\begin{aligned}
& \mathrm{Fe} \longrightarrow \mathrm{Fe}^{2+}+2 \mathrm{e} \\
& \mathrm{Fe}^{2+}+\text { plant extract } \longrightarrow[\mathrm{Fe} \text {-plant extract }]^{2+}
\end{aligned}
$$

The principal active component of methanolic extract is reported to be linalool, and its structure is given in Table 1 . The inhibition of methanolic extract of coriander seeds is primarily accredited to the linalool presence and other organic compounds (cumin aldehyde, cumin alcohol, eugenol, 3-allyl-6-methoxy phenol, and cryophllene oxide) in the extract. Thus, methanolic extract gets adsorbed on the C-steel surface, and a protective film is formed. This phenomenon might occur through the dipole interaction type between unshared electron pairs of oxygen atom or $\pi$-electrons (the extract aromatic ring constituents which considered a wealthy electron source) with the vacant, low energy d-orbitals of iron surface atom. Consistent with the literature molecule with $\mathrm{OH}$ groups, complexes with divalent ions may be willingly formed [20-22].

3.4. Electropolishing Rate Calculation. The electropolishing rate was computed according to the following equation:

$$
\mathrm{EP} \text { rate }=\frac{[W \text { before } \mathrm{EP}-W \text { after EP } / \text { area }]}{\text { Time }},
$$

where $W$ before EP is the weight of the test specimen before electropolishing and after surface preparation and $W$ after $E P$ is the weight after electropolishing. Area: $2 \mathrm{~cm} \times 2 \mathrm{~cm}$ ), and time is the electro-polishing time in seconds.

The electropolishing rate (EP rate) reduced with an augment in the methanolic extract concentration. Electropolishing rate measurements (Figure 6) confirmed the data

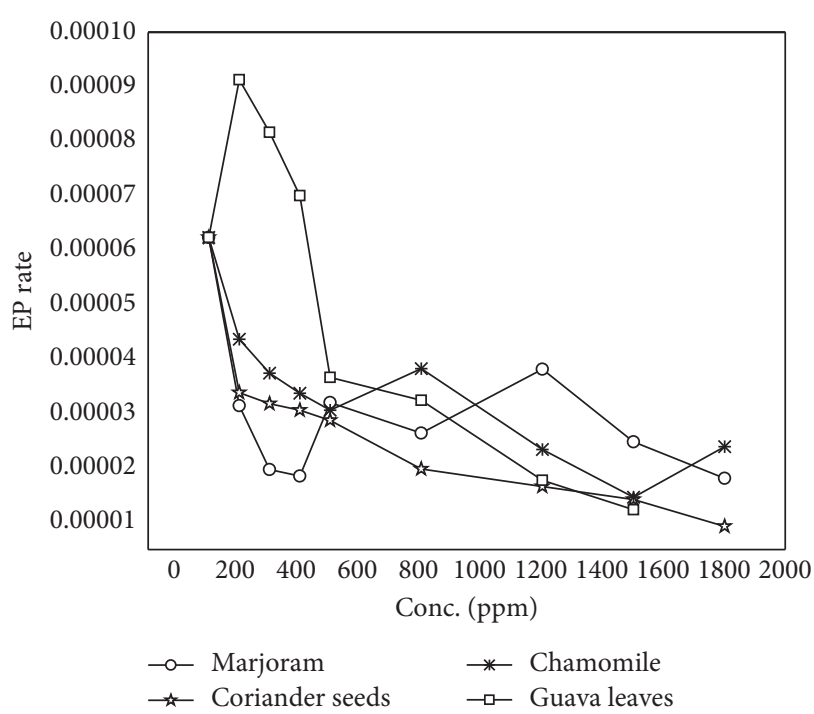

FIGURE 6: Electopolishing rate values for carbon steel in $8 \mathrm{M} \mathrm{H}_{3} \mathrm{PO}_{4}$ containing several concentrations of methanolic plant extract.

obtained from potentiodynamic measurements, where addition of methanolic plant extract retards the dissolution rate and the retardation behavior amplifies via mounting methanolic plant extract concentration [23].

3.5. Kinetic Point of View for the Electropolishing Process. In the present study of C- steel electropolishing in $\mathrm{H}_{3} \mathrm{PO}_{4}$ solutions, weight difference in the presence of different methanolic plant extracts at time $t$ is elected, $\Delta W$. When $\log W$ was plotted against time (in min), a linear variation was observed with high correlation coefficient for marjoram, coriander, and chamomile except guava leaves, which corroborates a first-order reaction kinetics with respect to C-steel in $\mathrm{H}_{3} \mathrm{PO}_{4}$ solutions in the presence of marjoram, coriander, and chamomile.

The first-order reaction kinetics equation is formulated as follows:

$$
\log \Delta W=\log \Delta W_{o}-k t,
$$

where $\Delta W_{o}$ is the weight difference in the $\mathrm{H}_{3} \mathrm{PO}_{4}$-free solution, $k$ is the rate constant, and $t$ is the time. The rate constants, $k$ values, obtained from the slopes of the plots in Figure 7 are presented in Table 3.

The results obtained reveal that the rate constant reduces with augment in plant extract concentration, and the halflife values, $t^{1 / 2}$ (Table 3 ), of the metal in the test solutions were calculated using the following equation:

$$
t^{1 / 2}=\frac{0.693}{k}
$$

The half-life values were observed to rise with amplification in the concentration of the methanolic plant extract, demonstrating diminishing in the metal dissolution rate in the solutions with increase in the methanolic plant extract concentration [24]. Also, the rate constant values and the half-life values, $t^{1 / 2}$, confirmed the result obtained from the 


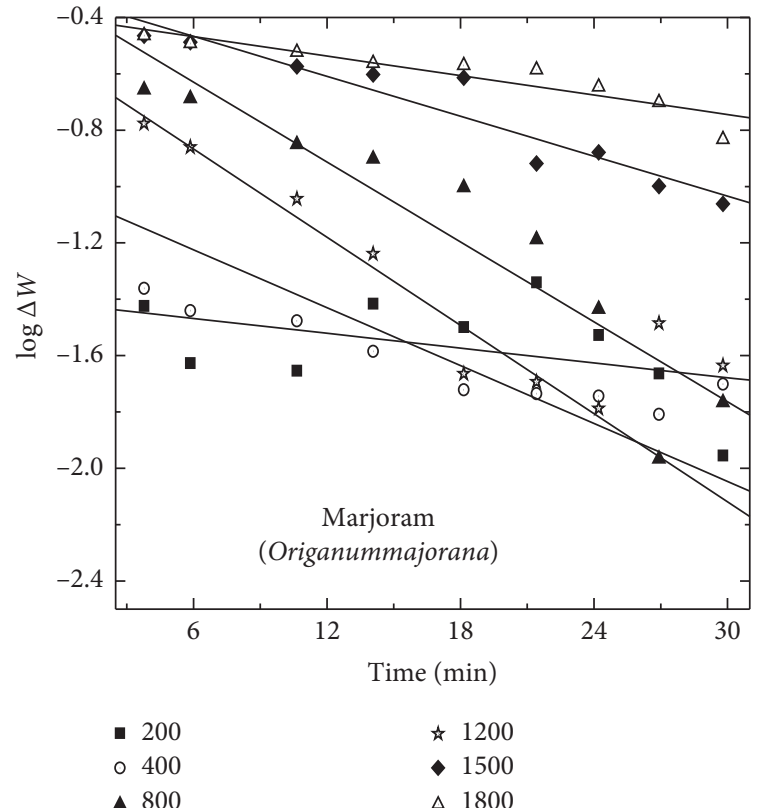

(a)

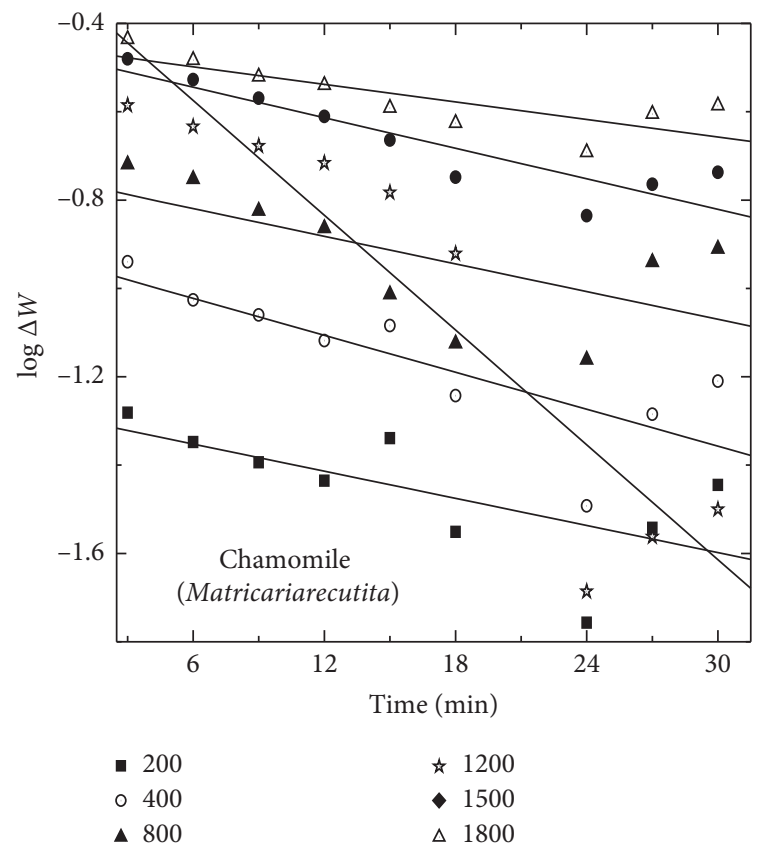

(c)

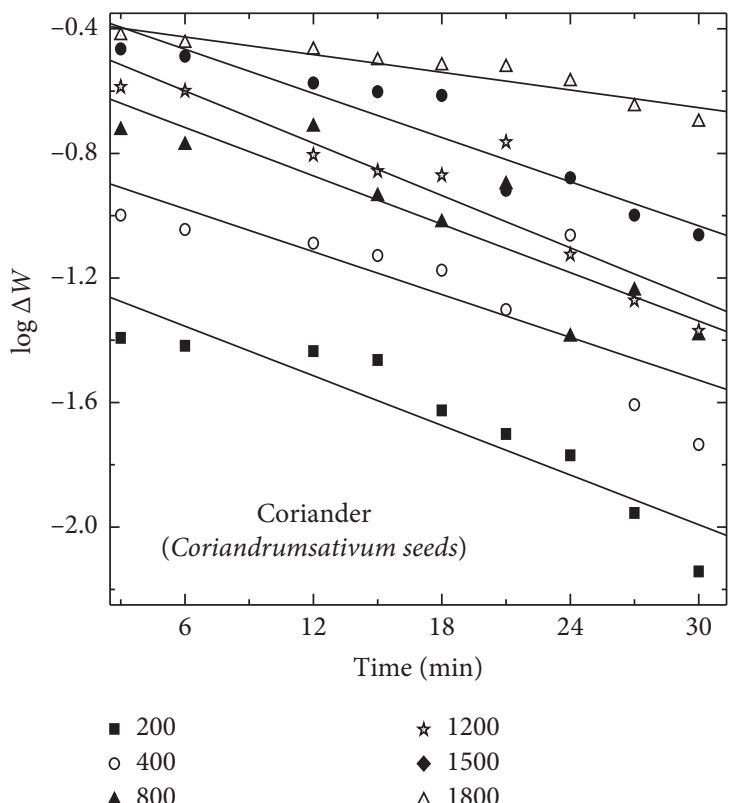

(b)

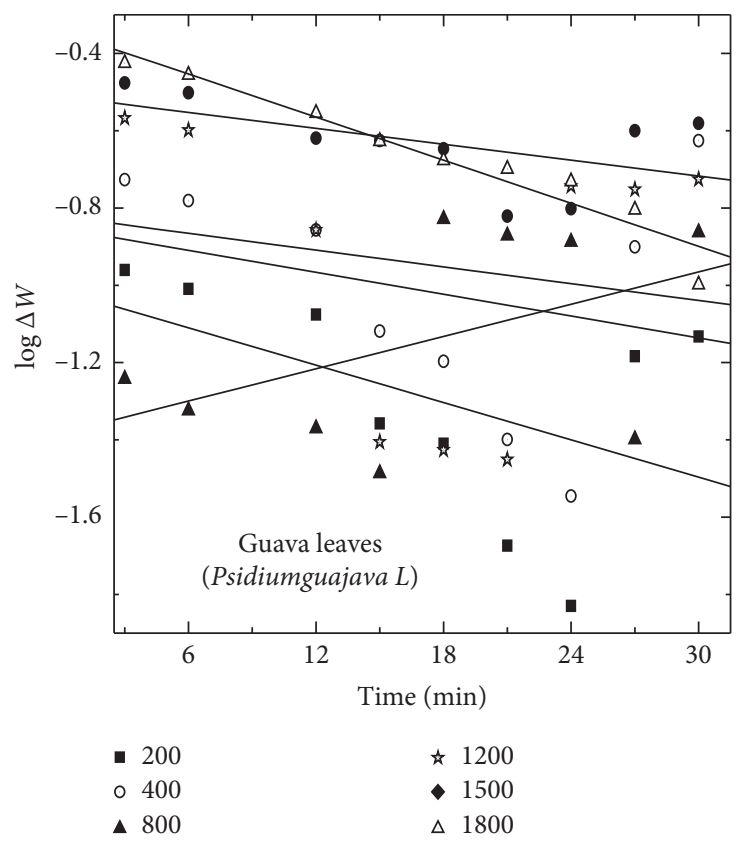

(d)

FIgURE 7: Variation of weight loss with time for mild steel (of a cross sectional area of $10 \mathrm{~cm}^{2}$ ) in $8 \mathrm{M} \mathrm{H} 3 \mathrm{PO} 4$ solutions containing methanolic extract: (a) marjoram, (b) coriander seeds, (c) chamomile, and (d) guava leaves at $25^{\circ} \mathrm{C}$.

TABLE 3: Rate constant and half-life time values for mild steel coupons in $8.0 \mathrm{M} \mathrm{H}_{3} \mathrm{PO}_{4}$ solutions containing different concentrations of methanolic plant extract using the weight loss technique.

\begin{tabular}{|c|c|c|c|c|c|c|c|c|}
\hline \multirow{2}{*}{ Methanolic extract Conc.(ppm) } & \multicolumn{2}{|c|}{ Marjoram } & \multicolumn{2}{|c|}{ Coriander } & \multicolumn{2}{|c|}{ Chamomile } & \multicolumn{2}{|c|}{ Guava leaves } \\
\hline & $k, \min ^{-1}$ & $t^{1 / 2}$ & $k, \min ^{-1}$ & $t^{1 / 2}$ & $k, \min ^{-1}$ & $t^{1 / 2}$ & $k, \min ^{-1}$ & $t^{1 / 2}$ \\
\hline 200 & 0.052 & 13.32 & 0.028 & 24.75 & 0.014 & 49.50 & 0.018 & 38.50 \\
\hline 600 & 0.047 & 14.74 & 0.026 & 26.65 & 0.0115 & 60.26 & 0.016 & 43.31 \\
\hline 800 & 0.034 & 20.38 & 0.025 & 27.72 & 0.006 & 115.50 & 0.013 & 53.30 \\
\hline 1200 & 0.023 & 30.13 & 0.023 & 30.13 & 0.004 & 173.25 & 0.006 & 115.50 \\
\hline 1500 & 0.011 & 63.00 & 0.022 & 31.50 & 0.0104 & 66.63 & 0.007 & 99.00 \\
\hline 1800 & 0.008 & 86.62 & 0.009 & 77.00 & 0.011 & 63.00 & 0.009 & 77.00 \\
\hline
\end{tabular}




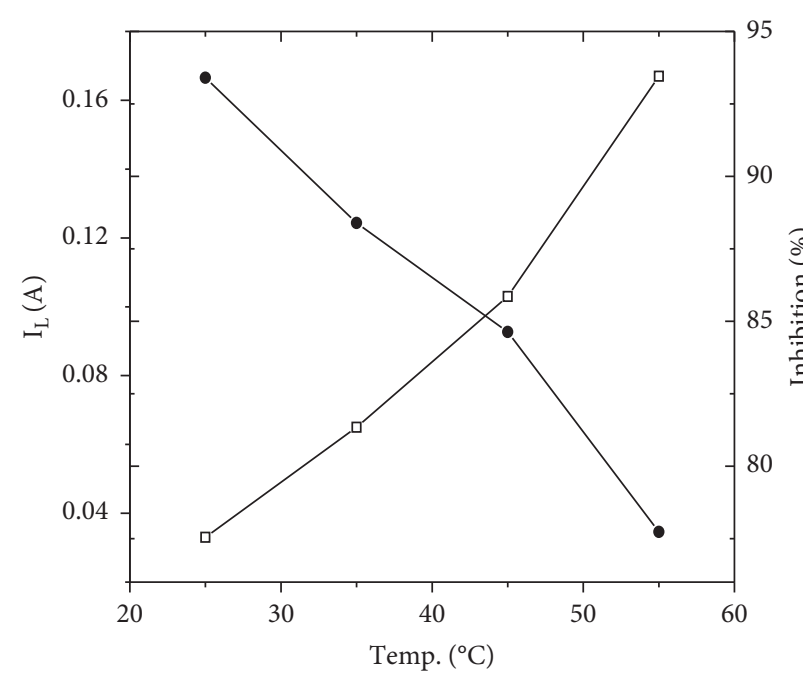

Marjoram

$\rightarrow-$ Limting current $\left(\mathrm{I}_{\mathrm{L}}\right)$

$\longrightarrow$ Inhibtion (\%)

(a)

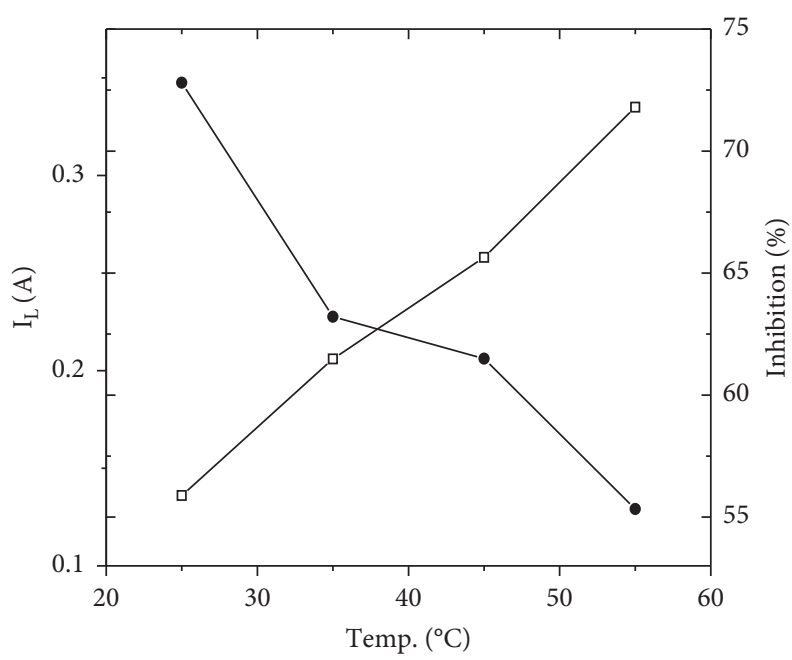

Chamomile

$\rightarrow \square$ Limting current $\left(\mathrm{I}_{\mathrm{L}}\right)$

$\multimap$ Inhibtion (\%)

(c)

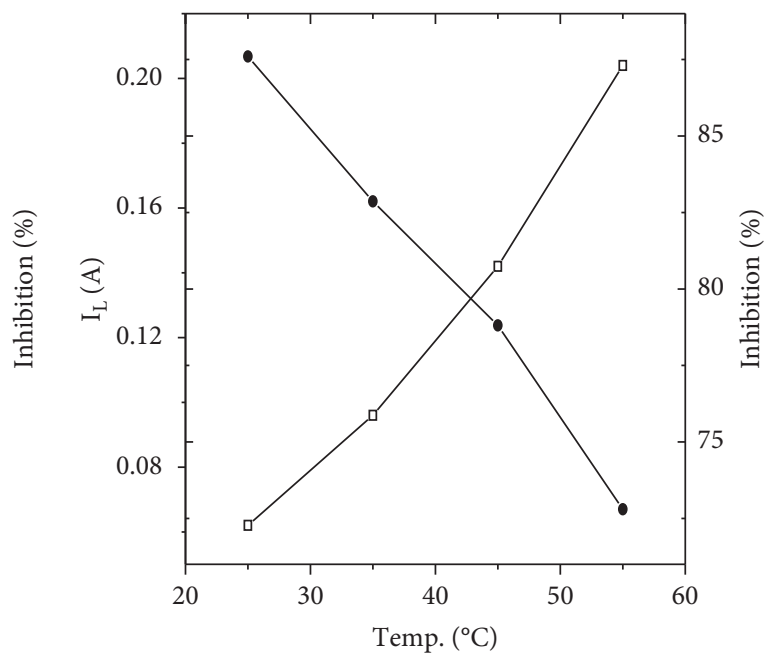

Coriander

$\rightarrow-$ Limting current $\left(\mathrm{I}_{\mathrm{L}}\right)$

$\rightarrow$ Inhibtion (\%)

(b)

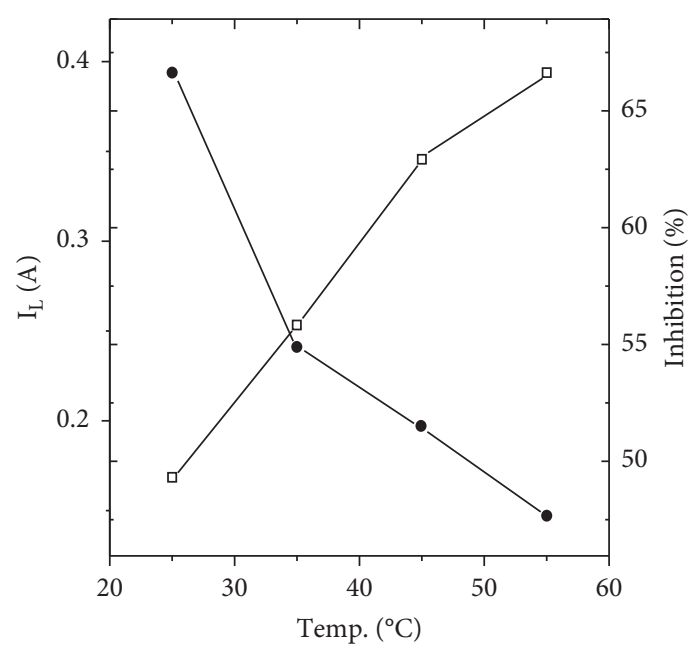

Guava leaves

$\rightarrow \square$ Limting current $\left(\mathrm{I}_{\mathrm{L}}\right)$

$\rightarrow$ Inhibtion (\%)

FIgURE 8: Variation of limiting current $\left(\mathbf{I}_{\mathbf{L}}\right)$ and \% inhibition with temperature $\left({ }^{\circ} \mathrm{C}\right)$ in the presence of $1800 \mathrm{ppm}$ of the four studied methanolic plant extracts.

glavonstatic technique and confirmed via SEM image and roughness values.

3.6. Temperature Influence. The temperature was found to be an extremely significant parameter for electropolishing. The limiting current augments via mounting of temperature from $25^{\circ}$ to $55^{\circ} \mathrm{C}$ are demonstrated in Table 2 and Figure 8.

The current increase with temperature risingis in conformity with the authors' observations [24]. This result may be related to equation (1) for the limiting current value. The temperature increase leads to amplification of the diffusion coefficient, $D$, of the rate limiting species values. The temperature is a function of $D$ according to equation (5).

$$
D=D_{o} \exp ^{-Q d / R T},
$$

where $D_{o}$ is the temperature-independent pre-exponential, $Q d=$ activation energy for diffusion, and $R$ is the gas constant $\left(8.314 \mathrm{~J} \cdot \mathrm{K}^{-1} \mathrm{~mol}^{-1}\right)$. 
The current variation with temperature may be attained via inserting equation (5) into (1):

$$
\mathbf{I}_{\mathbf{L}}=\frac{\mathbf{n Z F D}}{\boldsymbol{\delta}} C_{A l^{+3}} \exp ^{-Q d / R T}
$$

Taking the natural logarithm of both sides in equation (6) gives equation (7).

Equation (7) relates the bath temperature to the plateau current density (i.e., stable current density). Following this equation, it is obvious that the increase of the temperature would result in an exponential increase of the current density. However, it should be noticed that as the temperature rises, the viscosity of the diffusion layer on the anode surface is decreased, making it more difficult to maintain a viscous anode layer. This would inevitably affect the metal surface finish quality. In this sense, the temperature range to reach an optimum electropolishing result for a specific system should be carefully selected [25].

$$
\mathbf{L}_{\mathbf{n}} \mathbf{I}_{\mathbf{L}}=\ln \frac{\mathbf{n Z F D}}{\boldsymbol{\delta}} C_{\mathrm{Al}^{+3-Q d / R T}}
$$

Figure 9 demonstrates a curve of $\ln \mathbf{I}_{\mathrm{L}}$ vs. $\mathrm{T}^{-1}$ in a $8 \mathrm{M} \mathrm{H}_{3} \mathrm{PO}_{4}$-free solution and $8 \mathrm{M} \mathrm{H}_{3} \mathrm{PO}_{4}$ containing 1800 of the four studied methanolic plant extract. From Figure 7, assuming the activation energy would be allowed. In the current case, the activation energy (Ea) was approximately 11. $33 \mathrm{~kJ} \cdot \mathrm{mol}^{-1}$. The typical activation energy for the electrodissolution processes for $\mathrm{C}$ - steel in $8 \mathrm{M} \mathrm{H}_{3} \mathrm{PO}_{4}$ while in the presence of $1800 \mathrm{ppm}$ of marjoram, coriander seeds, chamomile, and Guava leaves is 43.34, 32.23, 23.87, and $123.50 \mathrm{~kJ} \cdot \mathrm{mol}^{-1}$, respectively. It was obvious that Ea amplified in the bath containing plant extract. The higher Ea values are an excellent confirmation for the strong retardation behavior of the four plant extract for the carbon steel electrodissolution $[7,26]$.

\subsection{Surface Characterization}

3.7.1. Scanning Elcectron Microscopy. The C-steel surface morphology of samples in the $8 \mathrm{M} \mathrm{H}_{3} \mathrm{PO}_{4}$-free solution and $8 \mathrm{M} \mathrm{H}_{3} \mathrm{PO}_{4}$ containing several concentrations of plant extract is revealed in Figure 10(a). The badly damaged and rough surface for raw the C-steel surface where there are severe damage, clear pits, and cavities. The surface heterogeneity is markedly observed. Inspections of the polished C-steel sample in the $8 \mathrm{M} \mathrm{H}_{3} \mathrm{PO}_{4}$ solution are shown in Figure 10(b); the surface morphology improved markedly, and there are fewer pits and cracks observed in the polished surface.

Figure 10(c) shows the C-steel surface after electropolishing in the $8 \mathrm{M} \mathrm{H}_{3} \mathrm{PO}_{4}$ solution containing $100 \mathrm{ppm}$ of marjoram methanolic extract. It is significant to point out that when the plant extract is added to the solution, the C-steel surface morphology is fairly dissimilar from the previous one and the surfaces were smoother to some extent. On studying the influence of higher concentration of the marjoram methanolic extract (500 ppm) on the C-steel in the $8 \mathrm{M} \mathrm{H}_{3} \mathrm{PO}_{4}$ solution (Figure 10(d)), we observed the film formation that is spread on the whole C-steel surface via a random way. This

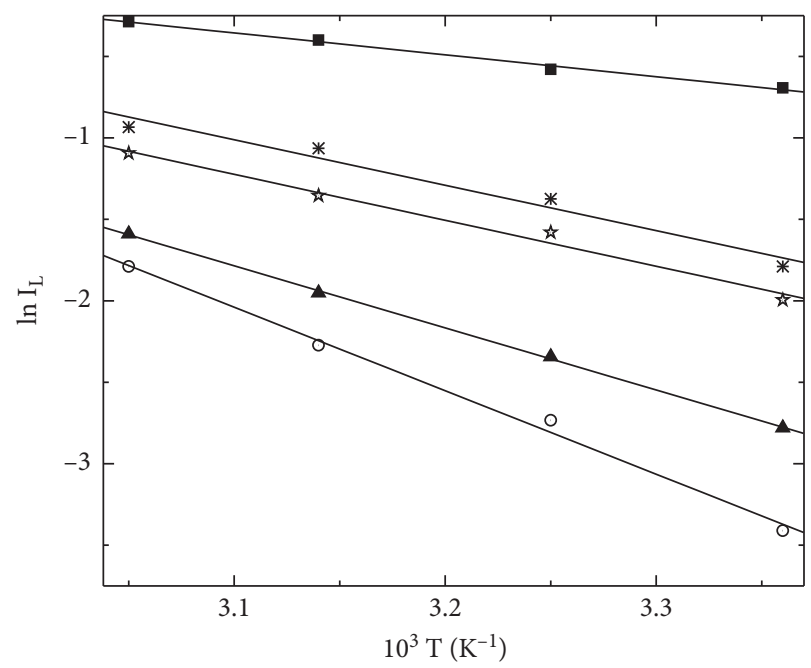

- $8 \mathrm{MH} 3 \mathrm{PO} 4$-free solution

- Marjoram (Origanummajorana)

^ Coriander (Coriandrumsativum)

* Chamomile (Matricariarecutita)

* Guava Leaves (Psidiumguajava L)

FIGURE 9: Arrhenius plot of the dissolution process recorded for the carbon steel plate in $8 \mathrm{M} \mathrm{H}_{3} \mathrm{PO}_{4}$ in the absence and presence of $1800 \mathrm{ppm}$ of the four plant extracts.

may be understood as owing to marjoram extract adsorption on the C-steel surface slot in the passive film, so it blocks the peaks and valleys on the C-steel surface, or owing to the extract molecules involvement and the interaction with the C-steel surface reaction sites, leading to a reduce in the contact between C-steel and the aggressive medium and successively displaying excellent retardation influence.

Figure 10(e) demonstrates SEM analysis of the C-steel after polishing in the $8 \mathrm{M} \mathrm{H}_{3} \mathrm{PO}_{4}$ solution containing 100 ppm coriander seeds extract. It can be observed that the surface has been moderately smooth in comparison with the $8 \mathrm{M} \mathrm{H}_{3} \mathrm{PO}_{4}$ without extracts sample, the dissimilarity becomes distinguished, mainly in orientation to the morphology obtained, and the grain boundaries are the main feature of the surface. But, the surface in the existence of 500 ppm coriander seeds extract (Figure 10(f)) was silky and minimal affected by the process of dissolution than the blank owing to the coriander seeds extract molecules adsorption on the C-steel surface and made a preservative layer on the surface. The formations of scattered pits are further diminished owing to involvement of coriander seeds extract molecules in pits and grain boundaries.

SEM C-steel surface images in the solution containing $100 \mathrm{ppm}$ and $500 \mathrm{ppm}$ chamomile extract are shown in Figures $10(\mathrm{~g})$ and $10(\mathrm{~h})$. The carbon steel surface is strongly influenced by the concentration of extract, it is monitored that there is a gradual increase in surface quality and uniformity by increasing extract concentration from 100 to $500 \mathrm{ppm}$, and the surface is well polished, smooth, and completely uniform since grain boundaries represented in Figure 10(h) clearly became completely disappeared in the presence of high concentration of chamomile extract, where chamomile extract molecules are filling up the grain 


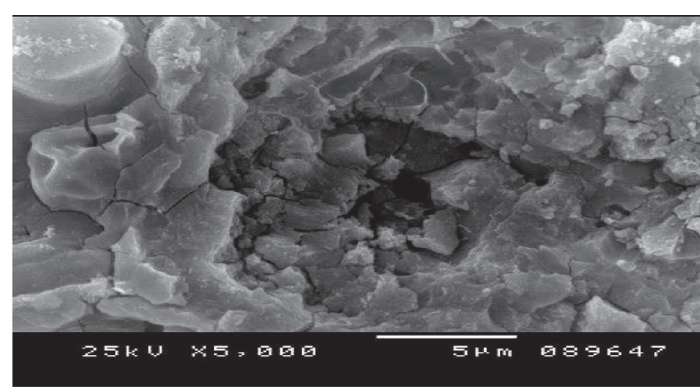

(a)

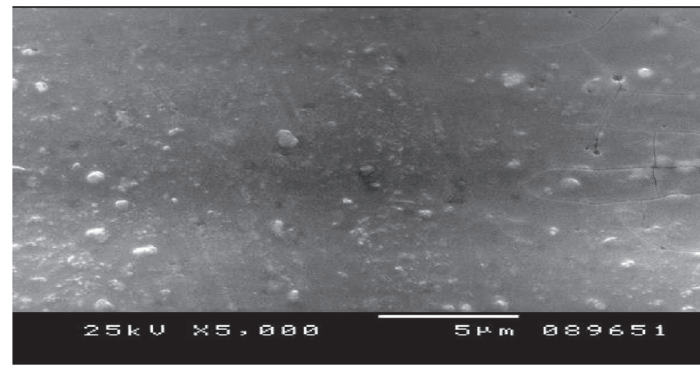

(c)

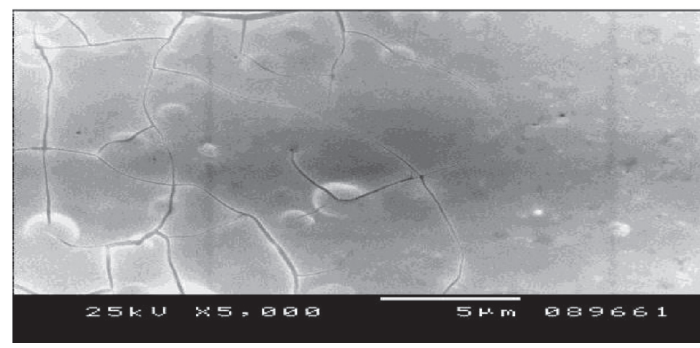

(e)

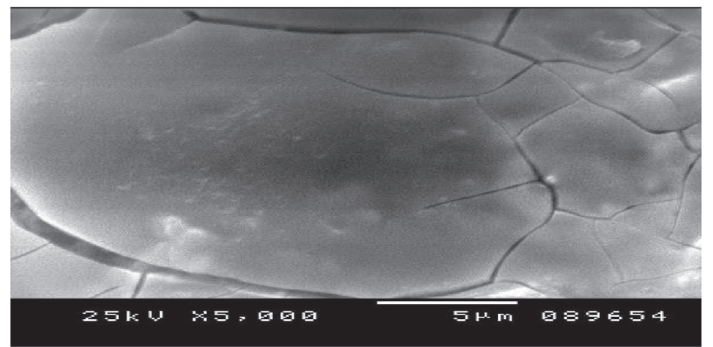

(g)

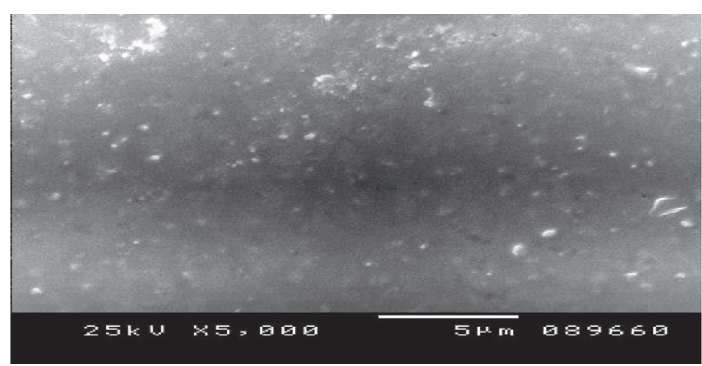

(i)

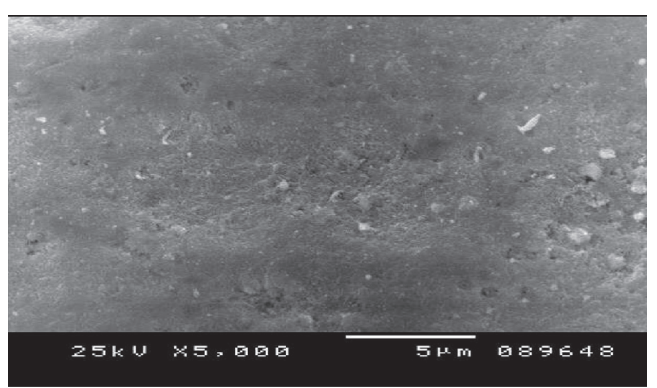

(b)

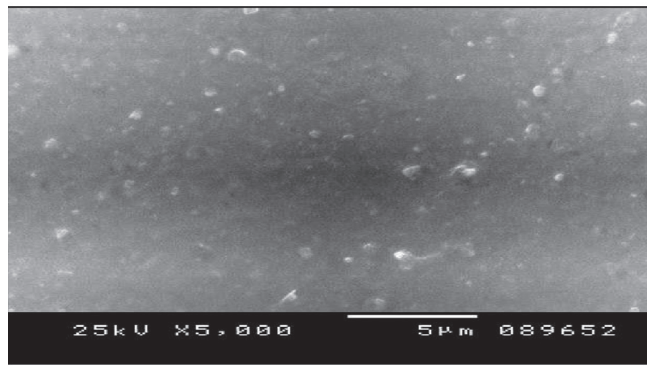

(d)

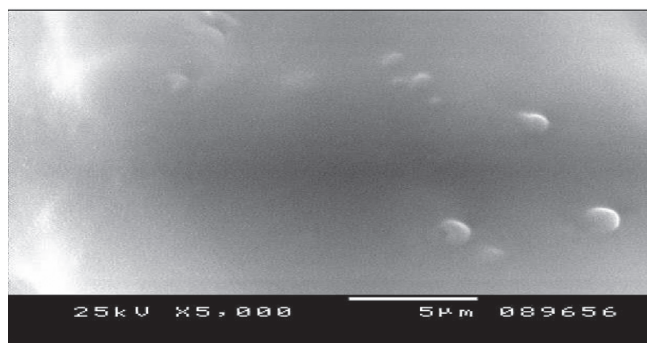

(f)

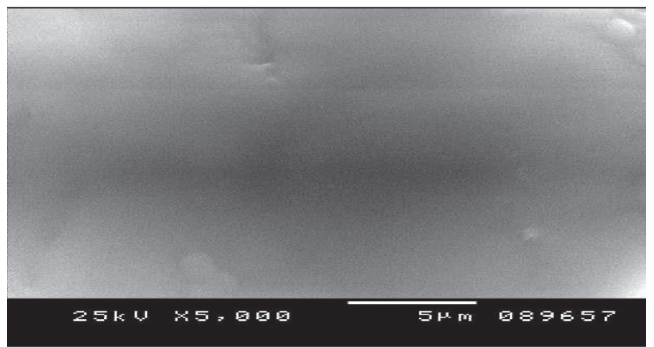

(h)

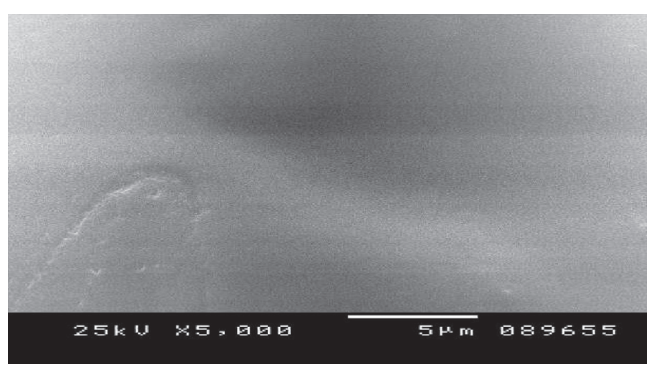

(j)

FiguRE 10: C-steel surface morphology before and after electropolishing at $298 \mathrm{~K}$ in the absence and presence of natural extracts. (a) Raw Csteel sample before EP. (b) After EP without addition (blank). (c) After EP + 100 ppm guava leaves extract. (d) After EP + 500 ppm guava leaves extract. (e) After EP +100 ppm chamomile extract. (f) After EP +500 ppm chamomile extract. (g). After EP +100 ppm coriander seeds extract. (h) After EP +500 ppm coriander seeds extract. (i) After EP +100 ppm marjoram extract. (j) After EP +500 ppm marjoram extract. 
TAble 4: Measured roughness (Ra), Rq (RMS), Peak-valley ratio, and brightness of C-steel samples.

\begin{tabular}{|c|c|c|c|c|c|}
\hline Sample & EP conditions & Brightness (gloss value) & Peak-valley ratio $(\mu \mathrm{m})$ & $\mathrm{Ra}(\mu \mathrm{m})$ & $\mathrm{Rq}(\mathrm{RMS})(\mu \mathrm{m})$ \\
\hline$A$ & Before electropolishing & 11.1 & 4.8 & 2.7 & 3.4 \\
\hline$B$ & After EP without additives & 16.0 & 0.47 & 0.52 & 0.66 \\
\hline C & After EP + 100 ppm guava leaves & 18.0 & 0.40 & 0.44 & 0.56 \\
\hline$D$ & After EP +500 ppm guava leaves & 24.5 & 0.30 & 0.28 & 0.32 \\
\hline E & After EP + 100 ppm chamomile & 18.4 & 0.36 & 0.40 & 0.52 \\
\hline$F$ & After EP + 500 ppm chamomile & 27.0 & 0.29 & 0.23 & 0.23 \\
\hline G & After EP +100 ppm coriander seeds & 19.2 & 0.34 & 0.36 & 0.48 \\
\hline$H$ & After EP +500 ppm coriander seeds & 56.59 & 0.28 & 0.21 & 0.22 \\
\hline$I$ & After EP + 100 ppm marjoram & 21.9 & 0.31 & 0.32 & 0.42 \\
\hline$J$ & After EP $+500 \mathrm{ppm}$ marjoram & 64.9 & 0.22 & 0.17 & 0.20 \\
\hline
\end{tabular}

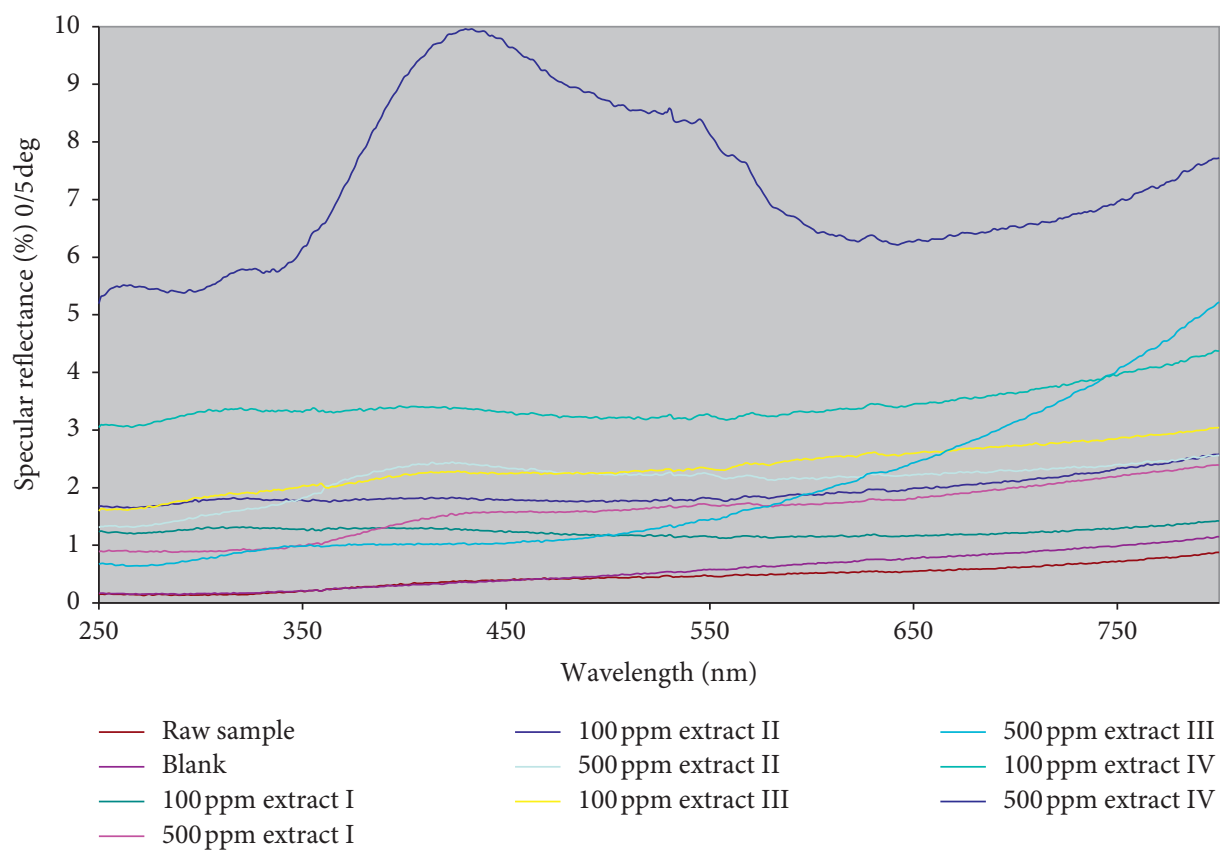

FIgURE 11: Reflectance diagram in the absence and presence of methanolic plant extract at different concentrations.

boundaries, as obtained in Figure 10(g). This led to improvement in surface quality resulting a completely uniform and smooth surface.

The C-steel surface electropolished in the $8 \mathrm{M} \mathrm{H}_{3} \mathrm{PO}_{4}$ solution containing $100 \mathrm{ppm}$ guava leaves extract (Figure 10(i)) is clear from any noticeable imperfections such as hollows and breaks, although some scratches are observable. In the presence of 500 ppm extract (Figure 10(j)), the C-steel cracks, heterogeneity, and pits are significantly reduced owing to the protective adsorption film formation offered by guava leaves extract, and clearly, a smooth and regular surface is noticed. The leveling and brightening influences were noticeably improved by the addition of Guava leaves extract where guava leaves extract are satisfying the channels and grain boundaries, and also, the etching effect is removed [27]

By comparing the effect of four extracts, it is noticed that the well-polished and uniform C-steel surface is obtained by the addition of $500 \mathrm{ppm}$ marjoram extract where a completely smooth, even, and uniform surface is obtained, and this behavior confirmed the data obtained from the polarization and weight loss method since marjoram extract records highest \% inhibition.

3.7.2. Surface Roughness. The proliferation and morphology of C-steel in the $8 \mathrm{M} \mathrm{H}_{3} \mathrm{PO}_{4}$-free solution and $8 \mathrm{M} \mathrm{H}_{3} \mathrm{PO}_{4}$ containing several plant extract were examined. According to Table 4, surface roughness, $\mathrm{Ra}$, peak to valley ratio, and $\mathrm{Rq}$ parameters for carbon steel samples on the $8 \mathrm{M} \mathrm{H}_{3} \mathrm{PO}_{4}$-free solution and $8 \mathrm{M} \mathrm{H}_{3} \mathrm{PO}_{4}$ containing several plant extract were represented. The same trend of $\mathrm{Ra}$ is observed for peak to valley ratio and $\mathrm{Rq}$ parameters.

Table 4 shows that the roughness $(\mathrm{Ra})$ diminished from $2.7 \mu \mathrm{m}$ to $0.52 \mu \mathrm{m} 8 \mathrm{M} \mathrm{H}_{3} \mathrm{PO}_{4}$-free solution. On the other hand, $\mathrm{Ra}$ was decreased from $0.44 \mu \mathrm{m}$ and $0.28 \mu \mathrm{m}$ by addition of 100 and 500 ppm of guava leaves extract.

The Ra decreases from $2.7 \mu \mathrm{m}$ to $0.40 \mu \mathrm{m}$ and $0.23 \mu \mathrm{m}$ in the presence of the two studied concentrations of chamomile extract. 
With respect to coriander seeds extract, Ra decreases from $2.7 \mu \mathrm{m}$ to $0.36 \mu \mathrm{m}$ and $0.21 \mu \mathrm{m}$ for 100 and $500 \mathrm{ppm}$, respectively [28].

The roughness $(\mathrm{Ra})$ value for carbon-steel specimen treated with $8 \mathrm{M} \mathrm{H} \mathrm{H}_{3} \mathrm{PO}_{4}$ solution containing 100 and $500 \mathrm{ppm}$ of marjoram extract recorded $0.32 \mu \mathrm{m}$ and $0.17 \mu \mathrm{m}$ as a minimum $\mathrm{Ra}$ value obtained.

The extract molecules behavior can be attributed to the extract adsorption ability on the C-steel surface. It amplifies via growing extract concentration.

Roughness measurements confirm scanning electron microscope images and will also be confirmed in the following brightness measurements section.

3.7.3. Gloss Value (Brightness). The Vis-IR spectra of untreated specimen, C-steel electropolished in $8 \mathrm{M} \mathrm{H}_{3} \mathrm{PO}_{4}$ (blank), and C-steel electropolished in $8 \mathrm{M} \mathrm{H}_{3} \mathrm{PO}_{4}$ electrolyte containing 100 and $500 \mathrm{ppm}$ of different plant extracts are shown in Figure 11.

It is seen that the electropolished specimens' reflectance is strongly affected by the type of plant extracts. It is clear that the reflectance of the specimen that is electro-polished at $8 \mathrm{M} \mathrm{H} \mathrm{H}_{3} \mathrm{PO}_{4}$ increases compared with the untreated specimen, where the specular reflectance value before EP is 11.1 and after $\mathrm{EP}$ in $8 \mathrm{M} \mathrm{H}_{3} \mathrm{PO}_{4}$ is 16 . High reflection property is obtained when the different type of plant extracts is added to the electropolishing electrolyte. By addition of guava leaves extract, chamomile extract, coriander seeds extract, and marjoram extract, the degree of surface brightness and reflectance increased; Table 4 .

In order to reduce the microirregularities and amplify the metal brightness, it is considered that it is essential to accomplish homogeneous formation and cations diffusion from the anode surface, on a microscale. It is credible that correct type and concentration of plant extract supply to control C-steel polishing in $\mathrm{H}_{3} \mathrm{PO}_{4}$ acid.

The adsorption enhancements and the normal anodic film action in improving the surface microstructure are credible from the four studied plant extracts.

\section{Conclusions}

(1) Addition of methanolic marjoram, coriander seeds, chamomile, and guava leaves extract to the electropolishing solution results in a lower limiting current.

(2) Qd increased in the presence of plant extract which is a good evidence of the strong retardation behavior of plant extract for the electrodissolution processes for C-steel.

(3) Activation parameters values confirm that the C-steel dissolution process was controlled by via diffusion and also it is endothermic in nature.
(4) According to SEM, UV-VIS-NIR spectra, and surface roughness easements, addition of moderate concentration (500 ppm) of methanolic plant extract to the electrolytic solution is highly effective to enhance C-steel surface quality.

(5) Reflection property is increased when the different types of methanolic plant extract are added to the electropolishing electrolyte. The addition of $500 \mathrm{ppm}$ of marjoram coriander, chamomile, and guava leaves increased the degree of surface brightness and reflectance to $64.9,56.59,27$, and 24.5 , respectively, relative to electropolishing electrolyte-free solution 16 .

(6) The roughness ( $\mathrm{Ra}$ ) decreased from $2.7 \mu \mathrm{m}$ to $0.52 \mu \mathrm{m}$ without addition of any material.

(7) $\mathrm{Ra}$ values are $0.28,0.23,0.21$, and $0.17 \mu \mathrm{m}$ in the presence of guava leaves, chamomile, coriander seeds, and marjoram [29].

\section{Data Availability}

The (limiting current table data and SEM data) data used to support the findings of this study are included within the article.

\section{Conflicts of Interest}

The authors declare that they have no conflicts of interest.

\section{References}

[1] N. Eliaz and O. Nissan, "Innovative processes for electropolishing of medical devices made of stainless steels," Journal of Biomedical Materials Research Part A, vol. 83, no. 2, p. 546, 2007.

[2] M. A. Deyab, "Corrosion inhibition of heat exchanger tubing material (titanium) in MSF desalination plants in acid cleaning solution using aromatic nitro compounds," Desalination, vol. 439, p. 73, 2018.

[3] A. S. Fouda, M. Diab, A. El-Sonbati, and S. A. Hassan, "Aqueous extract of propolis as corrosion inhibitor for carbon steel in aqueous solutions," African Journal of Pure and Applied Chemistry, vol. 7, no. 2, p. 67, 2013.

[4] A. Dafali, B. Hammouti, R. Touzani, S. Kertit, A. Ramdani, and K. El Kacemi, "Corrosion inhibition of copper in 3 per cent $\mathrm{NaCl}$ solution by new bipyrazolic derivatives," AntiCorrosion Methods and Materials, vol. 49, no. 2, p. 96, 2002.

[5] M. A. Hegazy, "A novel schiff base-based cationic gemini surfactants: synthesis and effect on corrosion inhibition of carbon steel in hydrochloric acid solution," Corrosion Science, vol. 51, no. 11, 2009.

[6] J. Hmimou, A. Rochdi, R. Touir et al., "Study of corrosion inhibition of mild steel in acidic medium by 2-propargyl-5-phlorophenyltetrazole: part i," Journal of Materials and Environmental Science, vol. 3, no. 3, p. 543, 2012.

[7] F. M. Abouzeid and H. A. Abubshait, "A study of vitamin B influence on the morphology, roughness, and reflectance of 
electropolished aluminum in $\mathrm{H}_{3} \mathrm{PO}_{4}-\mathrm{H}_{2} \mathrm{SO}_{4}$ mixture," Arabian Journal of Chemistry, vol. 13, no. 1, p. 2579, 2020.

[8] G. H. Sedahmed, M. S. Abdo, M. A. Kamal, O. A. Fadaly, and H. M. Osman, "A mass transfer study of the electropolishing of metals in mechanically agitated vessels," International Communications in Heat and Mass Transfer, vol. 28, no. 2, p. 257, 2001.

[9] A. A. Taha, F. M. Abouzeid, and M. M. Kandil, "Some drugs effect on the electropolishing of c-steel in $\mathrm{H}_{3} \mathrm{PO}_{4}$ acid under normal and compulsory convection circumstances," Russian Journal of Electrochemistry, vol. 56, no. 3, p. 189, 2020.

[10] K. K. Alaneme, S. J. Olusegun, and A. W. Alo, "Corrosion inhibitory properties of elephant grass (Pennisetum purpureum) extract: effect on mild steel corrosion in $1 \mathrm{M} \mathrm{HCl} \mathrm{so-}$ lution," Alexandria Engineering Journal, vol. 55, no. 2, p. 1069 , 2016.

[11] A. M. Abdel-Gaber, B. A. Abd-El-Nabey, I. M. Sidahmed, A. M. EL-Zayady, and M. Saadawy, "Inhibitive action of some plant extracts on the corrosion of steel in acidic media," Corrosion Science, vol. 48, no. 9, p. 2765, 2006.

[12] M. Shinitzky and R. Haimovitz, "Chiral surfaces in micelles of enantiomeric N-palmitoyl- and N-stearoylserine," Journal of the American Chemical Society, vol. 115, no. 26, Article ID 12545, 1993.

[13] K. Saito, H. Inoue, E. Kako et al., "Superiority of electropolishing over chemical polishing on high gradients," in Proceedings of the Workshop on RF Superconductivity, Abano Terme, Italy, 1997.

[14] R. K. Pathak and P. Mishra, "Drugs as corrosion inhibitors: a review," International Journal of Science and Research (IJSR), vol. 5 , no. 4 , p. $671,2013$.

[15] M. Abdallah, "Guar gum as corrosion inhibitor for carbon steel in sulfuric acid solutions," Portugaliae Electrochimica Acta, vol. 22, p. 16, 2004.

[16] G. Gunasekaran and L. R. Chauhan, "Eco friendly inhibitor for corrosion inhibition of mild steel in phosphoric acid medium," Electrochimica Acta, vol. 49, no. 25, p. 4387, 2004.

[17] A. S. Foudaa, A. Emamb, R. Refatc, and M. M. Nageeba, "Role of some thiadiazole derivatives as inhibitors for the corrosion of C-steel in $1 \mathrm{M} \mathrm{H}_{2} \mathrm{SO}_{4}$," Surface Engineering and Applied Electrochemistry, vol. 55, p. 294, 2019.

[18] A. Y. El-Etre, M. Abdallah, and Z. E. El-Tantawy, "Corrosion inhibition of some metals using lawsonia extract," Corrosion Science, vol. 47, no. 2, p. 385, 2005.

[19] R. Brouillard and O. Dangles, "The flavonids," Advances in Research since 1986, Champman \& Hall, London, UK, 1993.

[20] O. K. Abiola, A. O. C. Aliyu, A. A. Phillips, and A. O. Ogunsipe, "The effects of Phyllanthus amarus extract on corrosion and kinetics of corrosion process of aluminum in $\mathrm{HCl}$ solution," Journal of Materials and Environmental Science, vol. 4, p. 370, 2013.

[21] A. A. Taha, H. H. Abdel-Rahman, and F. M. Abozeid, "Effect of surfactants on the rate of diffusion controlled anodic dissolution of copper in orthophosphoric acid," International Journal of Electrochemical Science, vol. 8, p. 6744, 2013.

[22] R. S. Al-Moghrabi, A. M. Abdel-Gaber, and H. T. Rahal, "A comparative study on the inhibitive effect of Crataegus oxyacantha and Prunus avium plant leaf extracts on the corrosion of mild steel in hydrochloric acid solution," International Journal of Industrial Chemistry, vol. 9, no. 3, p. 255, 2018.

[23] F. M. Abouzeid, Int. J. Electrochem. Sci.vol. 11, p. 7269, 2016.

[24] C. Peter, E. Okafor, E. Ebenso, and J. E. Udofot, "Azadirachta indica extracts as corrosion inhibitor for mild steel in acid medium," International Journal of Electrochemical Science, vol. 5, pp. 978-993, 2010.

[25] G. Yang, B. Wang, K. Tawfiq, H. Wei, S. Zhou, and G. Chen, "Electropolishing of surfaces: theory and applications," Surface Engineering, vol. 23, 2016.

[26] A. Döner and G. Kardaş, "N-aminorhodanine as an effective corrosion inhibitor for mild steel in $0.5 \mathrm{M} \mathrm{H}_{2} \mathrm{SO}_{4}$," Corrosion Science, vol. 53, no. 12, p. 4223, 2011.

[27] A. A. Taha, A. M. Ahmed, H. H. A. Rahman, and F. M. Abouzeid, "The effect of surfactants on the electropolishing behavior of copper in orthophosphoric acid," Applied Surface Science, vol. 277, pp. 155-166, 2013.

[28] A. A. Taha, F. M. Abouzeid, M. M. Elsadek, and F. M. Habib, "Effect of methanolic plant extract on copper electro-polishing in ortho-phosphoric acid," Arabian Journal of Chemistry, vol. 13, no. 8, p. 6606, 2020.

[29] H. Tian, "The mechanism of electropolishing of niobium in hydrofluoric -sulfuric acid electrolyte," Journal of the Electrochemical Society, vol. 155, no. 9, p. 563, 2008. 